\title{
The Credibility Problem in Politics: Theory and Evidence from State-Level Abortion Legislation.*
}

\author{
Francisco Rodríguez ${ }^{\dagger} \quad$ Eduardo Zambrano ${ }^{\ddagger}$
}

April 17, 2009

\begin{abstract}
This paper proposes a simple mechanism for evaluating the relevance of credibility problems in politics. If parties are capable of making credible policy promises, we will not expect them to systematically adopt platforms that entail large probabilities of losing an election. This is because the adoption of very extreme platforms has the effect of shifting expected policies away from their ideal points. Parties who lack the capacity of making credible commitments, in turn, are unable to affect voters' expectations of the policies they will adopt upon reaching office. We test these predictions on a panel of US states by studying the relationship between the preferences of party constituents and enacted policies. We estimate this relationship using an econometric methodology that fully accounts for the possibility of multiple equilibria and find that its slope is in general not positive, a result that is inconsistent with the existence of a commitment technology.
\end{abstract}

Keywords: Credibility and commitment, Downsian competition, abortion legislation, quantile regressions, multiple equilibria.

*The authors would like to thank María Eugenia Boza, Michael Coppedge, Rafael DiTella, John Griffin, Robert Fishman, Ricardo Hausmann, B.J. Lee, Scott Mainwaring, Daniel Ortega, Benjamin Radcliff, Dani Rodrik, John Roemer, Cameron Shelton, Jorge Vargas, Romain Wacziarg and participants at seminars at IESA, the University of Notre Dame, Cal Poly and at the 2006 Public Choice Society Meetings, the 2006 LACEA Meetings, the 2008 World Meeting of the Game Theory Society and the 2008 European Meeting of the Econometric Society for their suggestions. We thank Alfonso Miranda for sharing and answering questions about his QCOUNT Stata code. The research for this paper was conducted in part while Francisco was a Visiting Scholar at the Kellogg Institute of the University of Notre Dame. He is profoundly grateful for that institution's support. Reyes Rodríguez Acevedo provided first-rate research assistance. All errors are our responsibility.

${ }^{\dagger}$ Human Development Report Office, United Nations Development Programme, 304 East 45th Street, FF-12th Floor, New York, NY, 10017. Email: francisco.rodriguez@undp.org.

‡Department of Economics, Orfalea College of Business, Cal Poly, San Luis Obispo, CA 93407. Email: ezambran@calpoly.edu. 


\section{Introduction}

The traditional Downsian model of politics assumes that parties can credibly commit to keep their policy promises once they reach office. The availability of this commitment technology allows them to manipulate policy proposals so as to garner the fraction of votes that maximizes their probability of winning. Political competition thus leads to convergence of proposed policies to the median voter's ideal point. A number of refinements of this model have been proposed in the literature since Downs's 1957 contribution, many of which have attempted to reverse the problematic hypothesis of complete convergence in policy proposals implied by Downsian competition ${ }^{1}$. Until the late nineties, most of this literature generally took as given the underlying assumption of a perfect capacity of politicians to make credible commitments ${ }^{2}$. Besley and Coate (1997) and Osborne and Slivinsky (1996), however, showed that some of the key results of the Downsian model fall apart when the assumption of perfect credibility is relaxed. In particular, electoral competition need no longer lead towards full or even partial convergence in policy platforms once parties lose their ability to make credible promises. Indeed, a multiplicity of equilibria become feasible, some of which entail very extreme policies being proposed in equilibrium.

Testing for the existence of credibility problems in politics is a difficult task, partly because of the problems that the multiplicity of equilibria creates. In principle, if we had information on politicians' platforms and ideal points, we could compare these with the policies that are actually adopted upon reaching office in order to evaluate whether politicians live up to their promises.

Because of difficulties in measuring politicians' preferences and distinguishing them from their platforms, empirical work on testing for the existence of credibility problems has instead focused on testing other implications of credibility models. Roughly speaking, two different lines of research exist: one is to test the credibility model against a model of pure Downsian competition which predicts complete convergence in platforms, while a second one is to test the credibilty model against a model of imperfect Downsian competition that predicts partial convergence in platforms. An example of the first line of research is Chattopadhyay and Duflo's (2004) study of the effect of political reservations of Village Council head positions to females in India. In a pure Downsian world, policies do not depend on the identity of candidates and thus should not vary with political reservations. Chattopadhyay and Duflo find evidence of significant changes in spending priorties when political reservations are adopted, thus

\footnotetext{
${ }^{1}$ Useful surveys include Mueller (2003), Hinich and Munger(1997), and Roemer (2005).

${ }^{2}$ A notable exception is Alesina (1988), who studies the credibility problem within the framework of a repeated game in which reputational equilibria can play the role of commitment technologies.
} 
providing evidence that is inconsistent with the pure Downsian model but consistent with the existence of credibility problems or a model of partial Downsian convergence. Lee, Moretti and Butler (2004) provide an example of the second line of research. They note that in models of partial convergence observed policies should move closer to politicians' ideal points in reaction to an exogenous shock in their probability of winning. The authors find no evidence of such an effect in the voting records of members elected to the U.S. House of Representatives, a result that contradicts the partial convergence model and is consistent with the existence of credibility problems. Both of these papers use quasi-natural experiments (randomized assignment of political reservations in India, results of close elections in the U.S. House) to address possible endogeneity problems.

Our paper complements existing research by proposing an alternative simple way of discriminating between models that assume commitment and those that preclude it. The test is based on the following observation: the key distinction between politicians who can credibly commit to keep their promises and those who cannot is that the former can control the expectations of the policies that they will enact once they reach office. Suppose then that we can pinpoint a case in which policy positions appear to be set in a manner that is clearly inconsistent with optimizing behavior, in the sense that if parties were to change them they could increase their expected utility. Then we would have reason to doubt that parties have much control over these positions.

A simple example of a policy position that is inconsistent with optimizing behavior is a position that is so extreme that it ensures its party defeat at the polls. Adopting such a position brings no gains to the party, as it leads enacted policies to move away from his ideal point. If we see parties systematically adopting such positions, this may be symptomatic of their inability to credibly commit to a different position.

Examples of candidates whose positions were too extreme for their own good abound. Take the example of George McGovern's 1972 candidacy in the US presidential elections against Richard Nixon. Most political analysts believed there was a reasonable chance that Nixon would have been defeated in the 1972 election had he run against a more moderate candidate. Nixon won the 1972 election with a remarkable landslide, carrying more than $60 \%$ of the popular vote and losing only Massachusetts and the District of Columbia. The generalized perception was that George McGovern's candidacy, which proposed a $37 \%$ reduction in defense spending in the midst of the Cold War, was too radical to woo a majority of American voters (White, 1972, p. 123). By adopting such a radical platform, the democrats ensured Nixon's victory and the continuation of conservative policies.

McGovern's example is not isolated. Barry Goldwater's 1964 promise to make so- 
cial security voluntary and Walter Mondale's 1984 commitment to raise taxes are often seen as examples of misguided political choices that cost them the presidency. So was Mario Vargas Llosa's promise to carry out a shock-therapy stabilization programme in the 1990 Peruvian presidential election against Alberto Fujimori, or Carlos Menem's 2003 promise to dollarize the Argentine economy in his failed bid to recover the presidency after the collapse of the Argentine convertibility plan. Our examples beg the question of why these politicians did not choose to moderate their policy proposals. A conventional analysis of these examples would characterize them as gross miscalculations, based on mistaken beliefs about what voters' actual preferences really were. Under the alternative interpretation that we espouse, there is nothing irrational about these policy platforms. It wasn't George McGovern's policy platform that cost him the presidency: it was his preferences. Had he proposed a more moderate platform, voters would not have bought it.

In the next section we show that it is possible to empirically identify cases in which the policies that voters expect parties to carry out are too extreme to be the result of optimizing behavior in the presence of a commitment technology. We suggest to do this by studying the shape of the expected policy function, which maps politicians' platforms into expected policies. Optimizing parties that can make credible commitments will never situate themselves on a segment of that function in which further moderation would lead expected policies to be closer to their ideal points. Doing so would leave unexploited the possibility of increasing the expected payoff for the parties by driving policies closer to their optimum while lowering uncertainty at the same time. Although the expected policy function cannot be directly used in the presence of credibility problems, we show that the indirect expected policy function, which maps preferences of party constituents into observed policies, shares the same comparative statics implications of the expected policy function and can thus be used to test for the existence of credibility problems.

Another way in which our research complements the existing literature is that we face squarely, at the empirical stage, the potential inference problems that multiplicity of equilibria of the underlying political economy model of interest may have. Using the comparative statics hypothesis of a single equilibrium case when there exist multiple equilibria is a form of model misspecification that can easily lead to erroneous inferences. In this paper we adapt ideas from Echenique and Komunjer (2005), based on the estimation of conditional quantiles, to test comparative statics implications about the extremes of a set of equilibria. We show that the extreme equilibria of a commitment model with multiple equilibria inherit the comparative statics implications of a simple equilibrium model, allowing us to empirically evaluate the model's implications 
by studying the behavior of extreme equilibria at different quantiles. To the best of our knowledge, this is the first empirical paper in the field of political economy to implement a test that fully accounts for the effects that the existence of multiple equilibria in the data generating process may have on the observed relationships between exogenous and endogenous variables in the data. As such, the way in which we conduct our empirical work has the potential of being useful also in other economic situations where multiple equilibria cannot be ruled out.

The rest of the paper is organized as follows. Section 2 lays out the basic theory, introducing the direct and indirect expected policy functions and deriving the key comparative statics implications that emerge form it. Section 3 contains our empirical analysis, which uses data on abortion preferences and legislation for a panel of 50 states and the District of Columbia. We show that a substantial fraction of our estimates display a negative relationship between the policy preferences of Democrat and Republican constituents and enacted policies, in contrast to what one would expect if a commitment technology was present. Section 5 concludes with some comments on directions for further research.

\subsection{Heuristic Exposition}

We start out from a simple graphical presentation of our main idea. Denote a party's policy platform as $\pi_{i} \in R^{+}$, where $i=l, r$ denotes each of the two parties in a twoparty environment. Let $P_{l}\left(\pi_{l}, \pi_{r}\right)$ denote the probability that party $l$ wins the election given the policy that voters expect it to carry out if elected $\left(\pi_{l}\right)$ and that which they expect his opponent to carry out if elected $\left(\pi_{r}\right)$. Define the expected policy function, $\pi^{e}\left(\pi_{l}, \pi_{r}\right)$, as the expectation of the policy to be enacted given policy platforms:

$$
\pi^{e}\left(\pi_{l}, \pi_{r}\right):=E(\boldsymbol{\pi})=P_{l}\left(\pi_{l}, \pi_{r}\right) \pi_{l}+\left(1-P_{l}\left(\pi_{l}, \pi_{r}\right)\right) \pi_{r}
$$

Figure 1 plots an example of an expected policy function, for a fixed value of $\pi_{r}$. Generally, the expected policy function will have increasing and decreasing segments as drawn. Now suppose that $l$ were a credible party with an ideal policy $t_{l}$ lower than that of the right-wing party $\left(t_{r}\right)$. Since a credible party can convince voters that it will implement any policy that it promises to pursue, then it can move its proposal at will to any point on $\pi^{e}\left(\pi_{l}, \pi_{r}\right)$. Suppose now that in equilibrium it is proposing a policy platform $\pi_{l}^{A}$ which is on a decreasing segment of the expected policy function. It would then be better for $l$ to slightly moderate its strategy, say to $\pi_{l}^{B}$. At the new strategy, the expected policy will be $\pi^{e}\left(\pi_{l}^{B}, \pi_{r}\right)$, which is lower (and thus closer to his 
ideal point) than $\pi^{e}\left(\pi_{l}^{A}, \pi_{r}\right)$. It will also face a less risky lottery than it was facing before between the outcome in which it wins the election and $\pi_{l}^{B}$ gets implemented and that in which it loses and $\pi_{r}$ gets implemented, since $\pi_{l}^{B}$ is closer to $\pi_{r}$ than $\pi_{l}^{A}$ was. It thus follows that $\pi_{l}^{A}$ is not an optimal policy for a risk-averse credible left-wing party.

\section{[Insert Figure 1 here]}

Matters are different for a party that faces a credibility problem. Such a party cannot affect expected policies by moderating its platform because voters are convinced that it will always carry out his optimal policy $t_{l}$ if elected. Thus, it does not have the capacity to move along the expected policy function. In effect, voters will always expect non-credible politicians to carrry out their prefered policy $\left(\pi_{i}=t_{i}\right)$, so that they are in effect stuck at whatever segment on the expected policy function their ideal point falls on. It follows that it is perfectly feasible for non-credible politicians to be on the decreasing segment of the expected policy function. This contrast between the empirical implications of the models gives rise to our empirical strategy: to estimate the expected policy function and to identify whether parties tend to be located on the increasing or decreasing portions of this function.

As stated, estimating the expected policy function is unlikely to be feasible, as it requires us to observe $\pi_{i}^{*}$, the policies that voters expect politicians to carry out in equilibrium. However, as we will show below it is straightforward to establish that the equilibrium policies $\pi_{i}^{*}\left(t_{l}, t_{r}\right)$ for the parties are increasing in the parties' ideal policies. From this it follows that we can derive an indirect expected policy function as:

$$
\Pi^{e}\left(t_{l}, t_{r}\right):=\pi^{e}\left(\pi_{l}^{*}\left(t_{l}, t_{r}\right), \pi_{r}^{*}\left(t_{l}, t_{r}\right)\right)
$$

with the property that when politicians can make credible commitments $\Pi^{e}$ will be strictly increasing in both of its arguments.

Our result follows from the fact that whenever a party decides to adopt a more moderate policy position, it is trading off two effects of moderation. On the one hand, adopting a more moderate stance may move expected policies away from its ideal point. This will occur if the change in policies when it is elected outweighs the lower probability of losing the election. On the other hand, moderating its position will certainly imply decreasing the distance between the enacted policy if it wins and the enacted policy if it loses, and thus entails undertaking a safer bet. In equilibrium, parties will trade off these two effects until they find a policy proposal where the marginal loss from further moderation is exactly offset by the marginal gain in terms 
of reduced risk. It follows that credible parties will always situate themselves in a position in which further moderations would lead to movements in the expected policy away from their ideal points. Politicians whose ideal point is below that of their opponents will be in a range where increases in their policy proposals lead to increases in the expected policies; those that are above the ideal point of their opponents will be in a situation where decreases in their policy proposals lead to decreases in expected policies. Therefore the expected policy function must be positively sloped.

This does not happen if parties lack credibility, because in this case they cannot affect their probability of winning by moderating. Voters know that they will carry out their preferred policies and will pay no attention to any policy commitments that parties attempt to make. Therefore, it is perfectly possible for a party that lacks credibility to be situated in the downward-sloping segment of the expected policy function. It would be great for that party if he were able to moderate his policy proposals: it would lead expected policies to come closer to his own preferred policy and would also reduce the risk coming from the uncertainty over the policies enacted by different parties. But the party with a credibility problem may well be stuck in this range of the expected policy function because it has no capacity to affect the expected policy function: for voters its relevant platform comes not from what he says, but from what they know that it will do.

Our empirical work will concentrate on estimation of the slope of (2). In Section 4, we will use the preferences of the median Republican and Democrat constituent as our indicators of $t_{i}$. Note that in order for this to be a consistent strategy all that we need is that the preferences of the median party member and that of the party's nominee be positively related. This result is generally true regardless of whether parties face a credibility problem vis-a-vis their constituents. ${ }^{3}$

\section{Theoretical Framework}

The policy space is the interval $T=[0,1]$. All individuals have preferences described by a strictly concave utility function $V(t, \pi)$, where $t \in(0,1)$ is the unique maximum of $V$ in $T$ (the ideal policy point for the individual) and $\pi$ is the adopted policy. $V$ satisfies the property that $V(t, \pi)=V(t+d, \pi+d)$ for $t, \pi, t+d, \pi+d \in T$. There are

\footnotetext{
${ }^{3}$ It is trivially true if within-party competition is Downsian. For the case of credibilty problems, see Proposition 7 of Besley and Coate, which ensures that in a two-candidate equilibrium, the candidates' ideal points will be symmetrically distributed around the median, so that the expected ideal point of the elected candidate is equal to that of the median voter. An interesting possibility however, is that even in the presence of credibity problems parties may use the nomination process as a commitment device, nominating candidates who are more moderate than the median party member. In this case, the predictions of the commitment model would apply.
} 
two parties, $l$ and $r$, with ideal points $t_{l}<t_{r}$. We assume that if a party is indifferent between several policies given the policy adopted by its opponent then it will pick the policy that gives the party its highest chances of winning ${ }^{4}$. This and the the concavity of $V$ in $T$ has the implication that each party's best response correspondence $\varphi_{i}$ will be single-valued.

Voters' ideal points are distributed over the policy space $T$. In general, the distribution $\mathbf{G}$ of voters is unknown to the parties. The parties propose policies $\pi_{l}$ and $\pi_{r}$. Let $\mathbf{g}\left(\pi_{l}, \pi_{r}\right)$ be the proportion of voters who prefer $\pi_{l}$ over $\pi_{r}$ according to the true distribution of voters $\mathbf{G}$. Each party forms beliefs about $\mathbf{G}$ and, given the proposed policies, they estimate the probability of each party winning the election, that is $P_{l}\left(\pi_{l}, \pi_{r}\right)=\operatorname{Prob}\left(\mathbf{g}\left(\pi_{l}, \pi_{r}\right)>\frac{1}{2}\right)$ and $P_{r}=1-P_{l}$. Because of this uncertainty, the policy preferred by the median voter is uncertain.

In what follows the parties may or may not have access to a commitment technology. We first study two versions of the model with commitment: One with specific functional forms for the utility function and the beliefs of the parties and a more general version of the model, consistent with a large variety of preferences and beliefs for the parties. Next we illustrate what happens if parties cannot commit to a particular policy platform.

\subsection{Example of a model with commitment}

In this model party $l$ with ideal point $t_{l}$ sets its policy $\pi_{l}$ to solve

$$
\max _{\pi_{l}} P_{l}\left(\pi_{l}, \pi_{r}\right) V\left(t_{l}, \pi_{l}\right)+\left(1-P_{l}\left(\pi_{l}, \pi_{r}\right)\right) V\left(t_{l}, \pi_{r}\right)
$$

taking $\pi_{r}$ as given. Party $r$ with ideal point $t_{r}$ sets $\pi_{r}$ to solve

$$
\max _{\pi_{r}} P_{r}\left(\pi_{l}, \pi_{r}\right) V\left(t_{r}, \pi_{r}\right)+\left(1-P_{r}\left(\pi_{l}, \pi_{r}\right)\right) V\left(t_{r}, \pi_{l}\right)
$$

taking $\pi_{l}$ as given.

In this sub-section we consider the case where $V_{i}(a)=-\left(t_{i}-\pi\right)^{2}$ and assume, as in Roemer (2001, p. 69) that the parties are polarized in their interests in that $t_{l}<\frac{1}{2}<t_{r}$. We also follow Roemer (2001, p. 45) by modeling the proportion $\mathbf{g}\left(\pi_{l}, \pi_{r}\right)$ of voters who prefer $\pi_{l}$ over $\pi_{r}$ as given by $\frac{\pi_{l}+\pi_{r}}{2}+\epsilon$, where $\epsilon$ is a random variable uniformly distributed on the interval $[-\beta, \beta]$, for some small positive $\beta$. The interpretation is that, given the policy proposals adopted by the parties, parties are confident of the proportion of voters who prefer $\pi_{l}$ over $\pi_{r}$ only up to a margin of error. From this

\footnotetext{
${ }^{4}$ We assume further that if the party cannot affect it's chances of winning then the party adopts its preferred policy as it's platform.
} 
it follows that in this model the probability that $l$ defeats $r$ when they respectively promise $\pi_{l}$ and $\pi_{r}$ is:

$$
\begin{aligned}
\left.P_{l}\left(\pi_{l}, \pi_{r}\right)\right|_{\pi_{l}<\pi_{r}} & =\left\{\begin{array}{cc}
0 & \text { if } \frac{\pi_{l}+\pi_{r}}{2}+\beta<\frac{1}{2} \\
\frac{1}{2}+\frac{\pi_{l}+\pi_{r}-1}{4 \beta} & \text { if } \frac{\pi_{l}+\pi_{r}}{2} \in\left[\frac{1}{2}-\beta, \frac{1}{2}+\beta\right], \\
1 & \text { if } \frac{\pi_{l}+\pi_{r}}{2}-\beta>\frac{1}{2}
\end{array}\right. \\
\left.P_{l}\left(\pi_{l}, \pi_{r}\right)\right|_{\pi_{l}=\pi_{r}} & =\frac{1}{2}, \text { and } \\
\left.P_{l}\left(\pi_{l}, \pi_{r}\right)\right|_{\pi_{l}>\pi_{r}} & =1-\left.P_{l}\left(\pi_{r}, \pi_{l}\right)\right|_{\pi_{r}<\pi_{l}}
\end{aligned}
$$

Let $\left(\pi_{l}^{*}, \pi_{r}^{*}\right)$ be the Nash equilibrium of this game with commitment. Our main goal in this sub-section is to show that in this simple model the policies adopted in equilibrium, and hence the expected policies, are increasing in the parties' preferred policies.

Given the structure adopted above it is not hard to show the following:

Lemma 1 In equilibrium $0<P\left(\pi_{l}^{*}, \pi_{r}^{*}\right)<1$ and $t_{l} \leq \pi_{l}^{*}<\pi_{r}^{*} \leq t_{r}$.

The proof follows from the fact that any policy proposal that a party can modify such that this modification would simulteaneously increase its chances of being elected while at same time getting the party closer to its ideal point cannot be an equilibrium.

For a formal proof of this and all the other results in this Section please see the Online Appendix. ${ }^{5}$

The next step is to show that, at the Nash equilibrium, the reaction functions of the parties are upward sloping.

Lemma $\left.2 \frac{\partial \varphi_{l}\left(\pi_{r}, t_{l}\right)}{\partial \pi_{r}}\right|_{\pi_{r}=\pi_{r}^{*}}>0,\left.\frac{\partial \varphi_{r}\left(\pi_{l}, t_{r}\right)}{\partial \pi_{l}}\right|_{\pi_{l}=\pi_{l}^{*}}>0$

The intuition behind this result is based on the fact that there are two effects of the increase in $\pi_{r}$ on party l's decision:

(i) It makes it more painful for party $l$ to lose, which will make party $l$ want to moderate its policy further to atenuate the probability of this ocurring. We call this the policy effect.

(ii) It increases party l's probability of winning. This effect may drive party $l$ ' platform towards its preferred policy. We call this the probability effect.

The lemma follows in this case because, for the specified utilities and beliefs chosen in this subsection, the overall effect always has the same sign as the policy effect.

\footnotetext{
${ }^{5}$ http://ssrn.com/abstract $=1390704$
} 
As the preferred policy of party $l$ increases, this will have as an effect to make the party's platform to increase as well, given party $r$ 's proposal. In other words, party l's reaction function "shifts to the right" as its preferred policy point moves to the right. Similarly for party $r$ (party r's reaction function "shifts up"). See Figure 2(a).

\section{[Insert Figure 2 here]}

Lemma $3 \frac{\partial \varphi_{l}\left(\pi_{r}^{*}, t_{l}\right)}{\partial t_{l}}>0, \frac{\partial \varphi_{r}\left(\pi_{l}^{*}, t_{r}\right)}{\partial t_{r}}>0$

The intuition is that as the leftist party suddenly becomes more conservative the cost from moderating its platform lessens, hence the party will moderate its policy more than before the change in preferences, to increase its probability of being elected.

\subsubsection{Equilibrium Comparative Statics}

Combining these lemmas yields the main result from this sub-section, which is illustrated in Figure 2(b):

Theorem $4 \frac{\partial \pi_{l}^{*}\left(t_{l}, t_{r}\right)}{\partial t_{l}}>0, \frac{\partial \pi_{l}^{*}\left(t_{l}, t_{r}\right)}{\partial t_{r}}>0$, similarly for party $r$.

Our main comparative statics result, the one we will bring to the data, pertains the (indirect) expected policy function, defined as

$$
\Pi^{e}\left(t_{l}, t_{r}\right):=\pi^{e}\left(\pi_{l}^{*}\left(t_{l}, t_{r}\right), \pi_{r}^{*}\left(t_{l}, t_{r}\right)\right)
$$

Corollary $5 \frac{\partial \Pi^{e}\left(t_{l}, t_{r}\right)}{\partial t_{l}}>0, \frac{\partial \Pi^{e}\left(t_{l}, t_{r}\right)}{\partial t_{r}}>0$

In words: for parties that can commit to a particular policy platform, as the preferred policies of the parties become more conservative, the policies that can be expected in equilibrium also become more conservative.

The intuition behind this last result was discussed at length above, in sub-section 1.1 .

\subsection{The general model with commitment}

One could wonder if the results obtained in the previous sub-section are an artifact of the specific utility function specified for the parties or of the particular way in which uncertainty about the distribution of voters is viewed by the parties. Below we show that the results hold in a vastly more general model than the one studied in the previous sub-section. 
As in the previous sub-section, in this model party $l$ with ideal point $t_{l}$ sets its policy $\pi_{l}$ to solve

$$
\max _{\pi_{l}} P_{l}\left(\pi_{l}, \pi_{r}\right) V\left(t_{l}, \pi_{l}\right)+\left(1-P_{l}\left(\pi_{l}, \pi_{r}\right)\right) V\left(t_{l}, \pi_{r}\right)
$$

taking $\pi_{r}$ as given. Party $r$ with ideal point $t_{r}$ sets $\pi_{r}$ to solve

$$
\max _{\pi_{r}} P_{r}\left(\pi_{l}, \pi_{r}\right) V\left(t_{r}, \pi_{r}\right)+\left(1-P_{r}\left(\pi_{l}, \pi_{r}\right)\right) V\left(t_{r}, \pi_{l}\right)
$$

taking $\pi_{l}$ as given. The difference here is that we do not pick a particular functional form for $V$ or $P$.

We do make, however, the following non-parametric assumptions about the distributions $P_{l}$ and $P_{r}$.

A0 (Symmetry) $P_{l}\left(\pi_{l}, \pi_{r}\right)=P_{r}\left(\pi_{r}, \pi_{l}\right)$

This says, in essence, that voters care about the policy that is adopted, and not about the identity of the party that implements it.

A1 (Uncertainty) $\pi_{l}=\pi_{r} \Rightarrow$ For some party $i \in\{l, r\} \exists \pi_{i}^{\prime}$ such that $\left|\pi_{i}^{\prime}-t_{i}\right|<$ $\left|\pi_{i}-t_{i}\right|$ and $P_{i}\left(\pi_{i}^{\prime}, \pi_{-i}\right)>0$.

This says, in essence, that the problem of determining who will win this election is non-trivial, that is, there can be some uncertainty over the winner if the parties do not adopt the same policies.

A2 (Monotonicity) $\pi_{l} \leq \pi_{l}^{\prime}<\pi_{r} \Rightarrow P_{l}\left(\pi_{l}, \pi_{r}\right) \leq P_{l}\left(\pi_{l}^{\prime}, \pi_{r}\right)$ and

$\pi_{r}<\pi_{l} \leq \pi_{l}^{\prime} \Rightarrow P_{l}\left(\pi_{l}, \pi_{r}\right) \geq P_{l}\left(\pi_{l}^{\prime}, \pi_{r}\right)$, similarly for $P_{r}$.

This says, in essence, that moving your proposal towards the policy of your opponent does not lower your chances of being elected. On the other hand, moving it away from that of your opponent may decrease them.

\subsubsection{Properties of the Nash equilibria of the game}

Lemma 6 Assume AO holds. Then $P_{l}\left(\varphi_{l}\left(\pi_{r}\right), \pi_{r}\right) \in(0,1]$. Similarly for party $r$.

Because party $l$ will never pick a policy that would guarantee a zero probability of victory in what follows we restrict the strategy space for party $l$, given $\pi_{r}$, to the set of policies $\pi_{l}$ for party $l$ such that $P_{l}\left(\pi_{l}, \pi_{r}\right) \in(0,1]$. Similarly for party $r$.

Lemma 7 Assume A0-A2 hold. Then in equilibrium $t_{l} \leq \pi_{l}^{*}<\pi_{r}^{*} \leq t_{r}$.

Notice that under A0-A2 from the argument espoused above the best response for party $l$ to $\pi_{r} \leq t_{r}$ satisfies $\varphi_{l}\left(\pi_{r}\right) \leq \pi_{r}$ and that there is no equilibrium with $\pi_{r}>t_{r}$. 
Consequently, in what follows we restrict the strategy space for party $l$, given $\pi_{r}$, to the set of policies $\pi_{l}$ for party $l$ such that $P_{l}\left(\pi_{l}, \pi_{r}\right) \in(0,1)$ and $\pi_{l} \leq \pi_{r}$. Similarly for party $r$.

Consider now the expected policy function,

$$
\pi^{e}\left(\pi_{l}, \pi_{r}\right):=P_{l}\left(\pi_{l}, \pi_{r}\right) \pi_{l}+\left(1-P_{l}\left(\pi_{l}, \pi_{r}\right)\right) \pi_{r}
$$

Lemma 8 Assume A0-A2 hold. Fix $\pi_{r}>t_{l}$ and let $\pi_{l}=\varphi_{l}\left(\pi_{r}\right)$. Pick $\pi_{l}^{\prime}>\pi_{l}$. Then $\pi^{e}\left(\pi_{l}^{\prime}, \pi_{r}\right) \geq \pi^{e}\left(\pi_{l}, \pi_{r}\right)$. Similarly for party $r$.

\subsubsection{The Nash equilibria of the game}

The following definition will be needed in what follows. The percent change in party l's probability of winning when going from $\pi_{l}$ from $\pi_{l}^{\prime}$, given $\pi_{r}$, is given by

$$
\Delta \% P_{l}\left(\pi_{l}, \pi_{l}^{\prime}, \pi_{r}\right)=\frac{P_{l}\left(\pi_{l}^{\prime}, \pi_{r}\right)}{P_{l}\left(\pi_{l}, \pi_{r}\right)}-1 .
$$

We make the following assumption regarding the behavior of $\Delta \% P_{l}$.

A3 (log supermodularity) $\Delta \% P_{l}\left(\pi_{l}, \pi_{l}^{\prime}, \pi_{r}^{\prime}\right) \geq \Delta \% P_{l}\left(\pi_{l}, \pi_{l}^{\prime}, \pi_{r}\right)$ for $\pi_{l} \leq \pi_{l}^{\prime}$ and $\pi_{r} \leq \pi_{r}^{\prime}$.

This says that the percent change in the probability of winning that follows a certain increase in party l's policy is no smaller when party $r$ 's policy is high than when party $r$ 's policy is low.

Lemma 9 Assume that A0-A3 hold. Then if $\pi_{r}^{\prime}>\pi_{r}$, then we have that $\varphi_{l}\left(\pi_{r}^{\prime}\right) \geq$ $\varphi_{l}\left(\pi_{r}\right)$.Similarly with the roles of the parties reversed.

The interpretation is that the best response function for party $l$ is non-decreasing in the policy of party $r$. Similarly for the best response function for party $r$. This is illustrated in Figure 2(c).

From the monotonicity of the best response function for both players and Tarski's theorem (c.f. Vives, 2001, p. 20) it follows that the set $E$ of Nash equilibria is nonempty and it has a greatest and a least element $\left(\bar{\pi}_{l}, \bar{\pi}_{r}\right)$ and $\left(\underline{\pi}_{l}, \underline{\pi}_{r}\right)$ in the sense that if $\pi^{*} \in E$ then $\underline{\pi} \leq \pi^{*} \leq \bar{\pi}$. This will be very important in what follows.

\subsubsection{Equilibrium Comparative Statics}

It turns out that under the assumptions espoused above the (expected) payoff function for party $l$ satisfies a single crossing property in $\left(\pi_{l}, t_{l}\right)$, and similarly for party $r$. 
Important comparative statics implications derive from this fact. Let $E V\left(t_{l}, \pi_{l}\right)$ denote the expected payoff function for party $l$ for a fixed policy $\pi_{r}$ for party $r$.

Lemma 10 Assume that A0-A2 hold. Then if $\pi_{l}^{\prime}>\pi_{l}$ and $t_{l}^{\prime}>t_{l}$ then we have that

$$
E V\left(t_{l}, \pi_{l}^{\prime}\right) \geq E V\left(t_{l}, \pi_{l}\right) \Rightarrow E V\left(t_{l}^{\prime}, \pi_{l}^{\prime}\right)>E V\left(t_{l}^{\prime}, \pi_{l}\right)
$$

and similarly for party $r$.

Theorem 11 Assume that A0-A3 hold. Then the largest and smallest Nash equilibria of the game, $\bar{\pi}$ and $\underline{\pi}$, are increasing in $t_{l}$ and $t_{r}$.

Figure 2(d) illustrates this result: the smallest equilibria of the model parametrized by $\left(t_{l}, t_{r}\right)$ is smaller than the smallest equilibria of the model parametrized by $\left(t_{l}^{\prime}, t_{r}^{\prime}\right)$, when $\left(t_{l}^{\prime}, t_{r}^{\prime}\right)>\left(t_{l}, t_{r}\right)$. Similarly for the largest equilibria of the models. Figure $2(\mathrm{~d})$ makes it clear that comparison of the rest of the equilibria may not even be meaningful, since the model parametrized by $\left(t_{l}, t_{r}\right)$ has an "intermediate" equilibrium but the model parametrized by $\left(t_{l}^{\prime}, t_{r}^{\prime}\right)$ does not.

In equilibrium, the indirect expected policy function can be computed as follows:

$$
\Pi^{e}\left(t_{l}, t_{r}\right)=\pi^{e}\left(\pi_{l}\left(t_{l}, t_{r}\right), \pi_{r}\left(t_{l}, t_{r}\right)\right)
$$

Let $\bar{\Pi}^{e}\left(t_{l}, t_{r}\right)$ and $\underline{\Pi}^{e}\left(t_{l}, t_{r}\right)$ be the indirect expected policy corresponding to the largest and smallest equilibrium respectively, and let $\mathcal{E}$ be the set of all policies that can arise in all of the equilibria of the model. In what follows members of $\mathcal{E}$ are called the equilibrium predictions of the model.

We know from Lemma 8 that the expected policy is increasing in $\pi_{l}$ and $\pi_{l}$ for rational politicians. From Theorem 11 we know that the largest and smallest Nash equilibria of the game, $\bar{\pi}$ and $\underline{\pi}$, are increasing in $t_{l}$ and $t_{r}$. It thus follows that the indirect expected policy function associated with the largest and smallest equilibria are also increasing in $t_{l}$ and $t_{r}$. This, together with Lemma 8 yields the following:

Corollary 12 If $t_{l}^{\prime} \geq t_{l}$ then $\bar{\Pi}^{e}\left(t_{l}^{\prime}, t_{r}\right) \geq \bar{\Pi}^{e}\left(t_{l}, t_{r}\right)$ and $\underline{\Pi}^{e}\left(t_{l}^{\prime}, t_{r}\right) \geq \underline{\Pi}^{e}\left(t_{l}, t_{r}\right)$. Similarly for $t_{r}^{\prime} \geq t_{r}$.

\subsection{A model without commitment}

When politicians cannot precommit to adopt a particular policy voters expect that, if elected, a party will adopt its most preferred policy. Therefore, the politicians cannot 
affect the probabilities of being elected and in the unique equilibrium, $\pi_{l}^{*}=t_{l}$ and $\pi_{r}^{*}=t_{r}$. Because of this, the adopted policies are trivially increasing in $t_{l}$ and $t_{r}$.

It turns out, however, that in the model without commitment Lemma 8 fails and hence the indirect expected policy function need not be increasing in the ideal points of the politicians, as in the model with commitment. We illustrate that this is the case with an example.

Consider the following partial specification of beliefs:

$$
P_{l}\left(\pi_{r}, \pi_{r}\right)=\left\{\begin{array}{cc}
\frac{\pi_{l}}{a} & \text { for } \pi_{l} \leq a \\
1 & \text { for } a<\pi_{l}<\pi_{r}
\end{array} \quad \text { where } \frac{\pi_{r}}{2}<a<\pi_{r}\right.
$$

Hence, the indirect expected policy function in this case satisfies

$$
\Pi^{e}\left(t_{l}, t_{r}\right)=\left\{\begin{array}{cc}
\frac{t_{l}}{a} t_{l}+\left(1-\frac{t_{l}}{a}\right) t_{r} & \text { for } t_{l} \leq a \\
t_{l} & \text { for } a<t_{l}<t_{r}
\end{array}\right.
$$

which is a decreasing function of $t_{l}$ when evaluating the function at any $t_{l}<\frac{t_{r}}{2}$. Hence, if the ideal point for party $l$ happens to be to the left of $\frac{t_{r}}{2}$, the indirect expected policy function will be decreasing in $t_{l}$ at that point.

In our empirical work we use the fact that the indirect expected policy function in the model with commitment responds differently to changes in $t_{l}$ and $t_{r}$ as the one in the model without commitment to identify how important the credibility problem is in practice.

\section{Statistical Framework}

When economic models of a situation of interest have multiple equilibria the standard practice is to impose additional assumptions so that the models yield a unique prediction. These additional assumptions are often very strong, and independent of the desired economic explanation. Moreover, they may be wrong, and this may pose a problem in the context of conducting proper inference on whether the comparative statics results developed above are consistent with observed data.

Traditional econometric analysis is based on the estimation of the conditional expected values of the variables of interest. If the polity underlying the situation under study, however, has multiple equilibria, the study of conditional expectations may yield the wrong inference.

To illustrate this consider a situation like the one depicted in Figure 3, which is an extension of the example depicted in Figure $2(\mathrm{~d})$. The situation is one in which 
there are two configurations for $t$ : "low" and "high." The polity defined by the low $t$ has three equilibria whereas the one defined by the higher $t$ has two equilibria. These equilibria come from a model like the one developed in sub-section 2.2 so that the extreme equilibria are monotonically increasing in $t$ as implied by Theorem 11 .

In this setting, the data that may be observed by an econometrician, conditional on $t$, may come from different equilibria that are observed imprecisely (as represented by the densities and the "arrows" depicted in Figure 3). Moreover, because nothing precludes for the proportion of data points that come from the different equilibria to vary with $t$, it can be that the estimated expected value of the endogenous variables conditional on $t$ may not pick up the monotonicity that is present in the structure of the polity, as shown in Figure 3(a). On the other hand, when we estimate sufficiently extreme conditional quantiles we are putting more weight on the data points that are more likely to be consistently coming from the extreme equilibria, and thus we are much more likely to capture any monotonicity relationship that may be present between parameters and the endogenous variables in the polity, as exemplified in Figure $3(\mathrm{~b})$.

\section{[Insert Figure 3 here]}

In light of the above, we conduct our empirical work "twice:" once under the assumption that the "true" model of the polity under study has only one Nash equilibrium, and then a second time under the assumption that multiple equilibria cannot be ruled out. The actual estimation of conditional quantiles (by means of quantile regressions) for the purpose of testing comparative static results arising from a model with multiple equilibria is a separate contribution of this paper as these ideas, to our knowledge, have never been applied to any data set.

\subsection{When the model has a unique equilibrium}

The econometrics behind the unique equilibrium case are standard. In this case our empirical work is concentrated on attempting to estimate the indirect expected policy function presented in (2). As we have shown, the credibility and commitment models have different implications for the slope of this function: under presence of a commitment technology, it is always positively sloped, whereas in their absence it can display a negative slope. In the next Section we evaluate these predictions using data on preferences over abortion and abortion legislation decisions in a panel of U.S. states. Expressions $\pi_{l}^{*}\left(t_{l}, t_{r}\right)$ and $\pi_{l}^{*}\left(t_{l}, t_{r}\right)$ define the equilibrium policies as a function of $t_{l}$, and $t_{r}$. Both of these equations define $E(\pi)$, whereas what we observe is the 
realization of $\pi$ :

$$
\pi_{i \tau}=E\left(\pi_{i \tau}\right)+\eta_{i \tau}=f\left(t_{l}, t_{r}\right)+\eta_{i \tau}
$$

where $\eta_{i \tau}$ refers to the effect on policies of the the realization of the uncertainty regarding $p\left(\pi_{l i \tau}, \pi_{r i \tau}\right)$ in state $i$ and year $\tau$. Note that the uncertainty captured in (5) is in essence an uncertainty regarding the true location of the median voter. As the preferences of the median voter in the state will in general not be orthogonal to the ideal points of the parties, it will be important to control for this term. Thus we decompose $\eta_{i \tau}$ into the part of it that depends on the preferences of the median voter and those that reflect the uncertainty arising from the impreciseness of the model:

$$
\eta_{i \tau}=\gamma \pi_{m i \tau}+\varepsilon_{i \tau}
$$

Adopting a linear form gives us our estimating equation:

$$
\pi_{i \tau}=\alpha_{0}+\alpha_{1} t_{r i \tau}+\alpha_{2} t_{l i \tau}+\gamma \pi_{m i \tau}+\varepsilon_{i \tau}
$$

Equation (6) thus allows us to nest the predictions from the commitment and the credibility models. In the model with commitment, $\alpha_{1}>0$ and $\alpha_{2}>0$. In the credibility model, no definitive prediction is made about the sign of $\alpha_{1}$ and $\alpha_{2}$. Nevertheless, we have shown that $\alpha_{1}<0$ and $\alpha_{2}<0$ are distinct possibilities in such a model. It follows that if our estimates of $\alpha_{1}$ and $\alpha_{2}$ are positive, we will be unable to distinguish between the two models, but if they are negative, it will be strong evidence against the commitment model. Parameter $\gamma$, in contrast, is premised to be positive in both models: given $\pi_{l}$ and $\pi_{r}$, an increase in $\pi_{m i \tau}$ leads to an increase in the probability that the highest proposed policy wins.

Our key tests will be focused on estimating an equation like (6). However, such an equation may not provide a very strong test against alternative theories of politics according to which other characteristics of the distribution of preferences affect policy outcomes. To take an example, theories of interest groups (Grossman and Helpman, 2002 ) tend to emphasize that some individuals (those who belong to better-organized groups) have a greater capacity to affect policies than others. In order to provide an empirical test that is strong against such type of competing hypotheses, we augment the regression in (6) as

$$
\pi_{i \tau}=\alpha_{0}+\alpha_{1} \pi_{r i \tau}^{*}+\alpha_{2} \pi_{l i \tau}^{*}+\alpha_{3} \mu_{1 i \tau}+\ldots+\alpha_{2+k} \mu_{k i \tau}+\gamma \pi_{m d i \tau}+\varepsilon_{i \tau}
$$

where $\mu_{1 i \tau} \ldots \mu_{k i \tau}$ are alternative characteristics of the distribution of voter prefer- 
ences, such as its conditional or unconditional moments. Equation (7) embodies the idea that any theory of politics is in effect a theory of the relationship between the distribution of policy preferences and policy outcomes.

\subsection{When the model has multiple equilibria}

Echenique and Komunjer (2005) show how comparative statics results like the ones we obtain in this paper translate into restrictions on the conditional quantiles of the endogenous variables. Under some regularity conditions, if the largest and the smallest equilibria are increasing in the exogenous variables, then a sufficiently high and a sufficiently low conditional quantile of the endogenous variables will also be increasing in the exogenous variables. Their framework makes no assumptions on the cardinality, location or probabilities over equilibria. In particular, they do not assume any kind of equilibrium selection rule. We can therefore potentially test whether a particular data set is consistent with the model with commitment by testing this monotonicity relationship between the ideal points of the parties and a sufficiently high conditional quantile of the policies that we can expect will be adopted in equilibrium.

To make this operational we estimate quantile regressions (Koenker, 2005), that is, we model the quantiles of the conditional distribution of the adopted policies as functions of the policy preferences of the politicians and other observed covariates, and examine the signs of the coefficients of those quantile regressions on the ideal points of the politicians. If the model with commitment is adequate for our data then we should expect those coefficients to be positive, for sufficiently high and sufficiently low conditional quantiles of the adopted policies.

The model without commitment, on the other hand, does not exhibit any multiplicity, and one can test whether the policies that we can expect will be adopted in equilibrium are increasing or decreasing in the parameters of interest by means of conventional least squares regressions.

\subsubsection{Multiple Equilibria Econometric Setup}

In what follows we consider the parameter set $T \ni t_{l}, t_{r}$ to be a finite set and define $\mathcal{T}=T \times T \subseteq \mathbb{R}^{2}$. We suitably adapt Echenique and Komunjer (2005) to our setting and define a reduced form model as a collection $\left(\left(\mathcal{E}_{t}, q_{t}\right), t \in \mathcal{T}\right)$ such that:

(1) for all $t, \mathcal{E}_{t} \subseteq \mathbb{R}_{++}$is finite and non-empty;

(2) $t<t^{\prime}$ implies that $\min \mathcal{E}_{t}<\min \mathcal{E}_{t^{\prime}}$ and $\max \mathcal{E}_{t}<\max \mathcal{E}_{t^{\prime}}$;

(3) for all $t, p_{t}$ is a probability distribution over $\mathcal{E}_{t}$ such that $p_{t}\left(\min \mathcal{E}_{t}\right)>0$ and $p_{t}\left(\max \mathcal{E}_{t}\right)>0$. 
Interpret this in light of the model developed in the previous section: $\mathcal{T}$ contains all possible ideal points for both parties, $\mathcal{E}_{t}$ is the set of policies that may end up being implemented in equilibrium when the ideal points of the politicians are given by $t \in \mathcal{T}$. The set $\Theta=\cup_{t \in \mathcal{T}} \mathcal{E}_{t}$ is the set of all possible values of the policy variable as $t$ varies in $\mathcal{T}$. The elements of $\Theta$ are denoted $\theta$. Let $\bar{\theta}_{t}=\max \mathcal{E}_{t}$ and $\underline{\theta}_{t}=\min \mathcal{E}_{t}$.

In Echenique and Komunjer (2005), the probability distribuition $p_{t}$ represents the unknown equilibrium selection process and so they range over the possible (deterministic) equilibria that can take place, conditional on $t$. Our setting differs from theirs in that here the econometrician does not observe the equilibria, but rather the policy that is adopted by the party that ends up winning the election. Therefore, in this paper the probability distribution $p_{t}$ is a mixture that arises out of combining some unspecified equilibrium-selection procedure with the probabilities that particular policies have of being adopted in equilibrium. Hence, if $E_{t}$ is the set of equilibrium policy profiles when the ideal points of the politicians are given by $t \in \mathcal{T}$ and $p_{E_{t}}$ is a probability distribution over $E_{t}$ such that $p_{E_{t}}\left(\min E_{t}\right)>0$ and $p_{E_{t}}\left(\max E_{t}\right)>0$, we then have that

$$
p_{t}(\theta)=\sum_{\pi \in E_{t}}\left[1_{\left\{\pi_{l}=\theta\right\}} P_{l}\left(\pi_{l}, \pi_{r}\right)+1_{\left\{\pi_{r}=\theta\right\}} P_{r}\left(\pi_{l}, \pi_{r}\right)\right] p_{E_{t}}(\pi) .
$$

With this modifications in place we can then apply the machinery of Echenique and Komunjer (2005) without further changes to derive conditions that allow the comparison of conditional quantiles for different values of $t$ to be a valid test of the comparative static results derived in Section 2.

The next step is to define our statistical reduced form model as

$\left(\left(\mathcal{E}_{t}, p_{t}\right),\left(H_{\theta, t}\right)_{\theta \in \mathcal{E}_{t}}, t \in \mathcal{T}\right)$ such that

(1) $\left(\left(\mathcal{E}_{t}, p_{t}\right), t \in \mathcal{T}\right)$ is a reduced-form model,

(2) for all $t \in \mathcal{T}$ and $\theta \in \mathcal{E}_{t}, H_{\theta, t}$ is a twice-differentiable distribution function on $\mathbb{R}_{++}$, with strictly positive density.

The model is to be interpreted as follows: Think of the realized policies in the data as coming from a multiplicative model

$$
\pi \equiv \theta \cdot \varepsilon
$$

where $\theta \in \mathcal{E}_{t}$ is an equilibrium prediction, drawn according to $p_{t}$, and $\varepsilon$ is a multiplicative random "error," drawn from distribution $H_{\theta, t}$. According to this $\pi$ is a random 
variable with distribution $F_{t}$ given by a discrete mixture of continuous distributions.

$$
F_{t}(y)=\sum_{\theta \in \mathcal{E}_{t}} p_{t}(\theta) H_{\theta, t}\left(\frac{y}{\theta}\right) \text { for any } y>0
$$

Given $\alpha \in(0,1)$, let $q_{\alpha}(\boldsymbol{\pi} \mid t)$ denote the $\alpha$-quantile of $\boldsymbol{\pi}$ conditional on $t$,

$$
q_{\alpha}(\boldsymbol{\pi} \mid t) \equiv \inf \left\{y \in \mathbb{R}_{++}: F_{t}(y)>\alpha\right\}
$$

and define $\bar{H}_{\theta, t}$ by $\bar{H}_{\theta, t} \equiv 1-H_{\theta, t}$.

Say that $\bar{H}_{\theta, t}$ is in $\mathcal{R}_{-\infty}$ at $\infty$ if for $\lambda>0$

$$
\lim _{y \rightarrow \infty} \frac{\bar{H}_{\theta, t}(\lambda y)}{\bar{H}_{\theta, t}(y)}=\lambda^{-\infty}
$$

Distributions in $\mathcal{R}_{-\infty}$ at $\infty$ are not very heavy tailed, meaning that their tails decrease to zero faster than any power law $y^{-\alpha}$.

Consider the following assumption on the structure of the tails $\bar{H}_{\theta, t}$ :

S2. Say that a statistical reduced-form model $\left(\left(\mathcal{E}_{t}, p_{t}\right),\left(H_{\theta, t}\right)_{\theta \in \mathcal{E}_{t}}, t \in \mathcal{T}\right)$ satisfies S2 if

(1) for every $t \in \mathcal{T}, \bar{H}_{\theta, t}$ is in $\mathcal{R}_{-\infty}$ at $\infty$;

(2) for every $\theta \in \Theta$ with $\theta<\bar{\theta}_{t} ; \frac{\bar{H}_{\theta, t}(y)}{\bar{H}_{\bar{\theta}_{t}, t}(y)}$ is bounded as $y$ goes to $\infty$; and

(3) for every $\left(t, t^{\prime}\right) \in \mathcal{T}^{2}$ with $t<t^{\prime}, \frac{\bar{H}_{\bar{\theta}_{t}, t}(y)}{\bar{H}_{\bar{\theta}_{t}, t^{\prime}}(y)}$ is bounded as $y$ goes to $\infty$.

Under this assumption one can establish an unambiguous connection between the parameters of interest and the conditional quantiles of $\pi$ under $F_{t}$.

Theorem 13 (Echenique and Komunjer, 2005) If $\left(\left(\mathcal{E}_{t}, p_{t}\right),\left(H_{\theta, t}\right)_{\theta \in \mathcal{E}_{t}}, t \in \mathcal{T}\right)$ satisfies S2 then for any $\left(t, t^{\prime}\right) \in \mathcal{T}^{2}$ :

(i) there is $\bar{\alpha} \in(0,1)$ such that $t<t^{\prime}$ implies $q_{\alpha}(\boldsymbol{\pi} \mid t)<q_{\alpha}\left(\boldsymbol{\pi} \mid t^{\prime}\right)$ for all $\alpha \in[\bar{\alpha}, 1)$.

The interpretation is that if the distribution $\bar{H}_{\theta, t}$ is not too heavy tailed the effect of $t$ on the largest equilibrium in $\mathcal{E}_{t}$ will eventually be noticed in the tail of $F_{t}$.

This result, properly transposed, holds for $\alpha$ sufficiently close to zero.

\subsubsection{Quantile regressions}

The argument just espoused essentially shows that, under some regularity conditions, sufficiently high and sufficiently low conditional quantiles of the adopted policies will be increasing in the ideal points of the parties. To estimate those conditional quantiles we now follow the general approach of Koenker (2005) and we fit 
quantile regressions corresponding to the quantiles $\{0.1,0.25,0.75,0.9\}$ to the data $\left\{\left(\pi_{1}, \pi_{2}, \ldots, \pi_{N}\right),\left(t_{1}, t_{2}, \ldots, t_{N}\right),\left(x_{1}, x_{2}, \ldots, x_{N}\right)\right\}$, where $N$ is the sample size, $\pi_{i}$ is the realized policy for observation $i, t_{i}$ is the profile of ideal points of the parties for observation $i$ and $x_{i}$ is a $d$-dimensional vector of controls for observation $i$. According to this methodology, one estimates the conditional quantile regression by minimizing a sum of asymmetrically weighted absolute residuals. Hence, if we wish to understand how the conditional quantiles depend on $t$, we can model them as functions $\widehat{q}_{\alpha}(\boldsymbol{\pi} \mid t, x, \beta)$, which can be found as the solution to

$$
\min _{\beta \in \mathbb{R}^{d+2}} \sum_{i=1}^{N} \rho_{\alpha}\left(\pi_{i}-\widehat{q}_{\alpha}(\boldsymbol{\pi} \mid t, x, \beta)\right),
$$

where

$$
\rho_{\alpha}(u)=\left\{\begin{array}{cc}
\alpha u & \text { if } u \geq 0 \\
(1-\alpha) u & \text { if } u<0
\end{array} .\right.
$$

We elaborate on the econometric issues regarding the edtimation of such quantile regressions for our panel of 50 states in sub-section 4.3 .

\section{Estimation}

\subsection{The Data}

Our paper will test the above derived hypotheses on a panel covering data on abortion legislation and preferences for the 50 United States. Although the model can in principle be applied to the study of the determination of any policy, we concentrate on abortion for several reasons. In the first place, the extensive interest on the abortion issue in the United States has led to the detailed documentation of voter preferences over time through opinion surveys like the General Social Survey (GSS) and National Election Studies (NES). Furthermore, the public opinion literature has found that abortion preferences are somewhat less susceptible to framing effects than many other public policies. Even though, as is generally the case in public opinion studies, the answers given to survey questions tend to be sensitive to changes in question wording, studies have found that respondents can accurately place themselves on abortion using a variety of question formats, and that the operationalization of attitudes towards abortion generally seems robust across different measurement strategies (Cook, et. al. 1993, Jelen and Wilcox, 2003). A last point has to do with the availability of significant variation across states and time in the adoption of legislative restrictions to abortion.

Both the NES and GSS have been measuring attitudes towards abortion since the 
1980s. The NES studies have posed the following question in every survey since 1980:

I am going to read you a short list of opinions. Please tell me which one of the opinions best agrees with your view. (1) By law, abortion should never be permitted, (2) The law should permit abortion only in case of rape, incest, or when the woman's life is in danger, (3) The law should permit abortion for reasons other than rape, incest, or danger to the woman's life, but only after the need for the abortion has been clearly established. (4) By law, a woman should always be able to obtain an abortion.

The GSS's question is the following:

Please tell me whether or not you think it should be possible for a pregnant woman to obtain an abortion... (1) if there is a strong chance of serious defect in the baby? (2) if she is married and does not want any more children?

(3) if the woman's own health is seriously endangered by the pregnancy? (4)if the family has a very low income and cannot afford any more children? (5) if she became pregnant as a result of rape? (6) if she is not married and does not want to marry the man? (7) if the woman wants it for any reason?

There is an obvious difference between the NES question and the GSS question. While in the NES case we have respondents' answers to one question, which is logically defined to progress from less inclusive to more inclusive definitions of permissible abortion, the GSS survey gives us the yes-no responses to seven different questions, without making it evident how to combine them into a single scale. One possibility is to follow conventional practice in the public opinion literature and build a 0-7 scale which captures the number of times that respondents answered each of these questions in the affirmative. We discuss alternative approaches below.

Our interest is in understanding how these preference indicators correlate with enacted abortion legislation across time in the 50 United States and the District of Columbia. We construct our indicators of the distribution of preferences over abortion policies for each state-year using conditional and unconditional moments and percentiles of the empirical distribution of preferences. Given each respondents' answer to the NES and GSS questions, we calculate the median preference over abortion restrictions $\left(\pi_{m i \tau}^{*}\right)$, the median preference of voters who self-identify as republicans $\left(t_{r i \tau}\right)$ and of those who self-identify as democrats $\left(t_{d i \tau}\right)$. We also construct several indicators of the distribution of preferences over abortion legislation $\mu_{1} \ldots \mu_{n}$, including the mean, standard deviation, skewness and kurtosis of this distribution as well as the average preference conditional diverse individual characteristics. We calculate 378 state-year observations based on 18409 individual-level survey responses for the NES data and 575 state-year observations based on 18976 individual-level survey responses for the GSS data. 
The use of these measures to proxy for the distribution of preferences within states at any given year may raise questions about reliability. The NES and GSS samples are designed to be representative at a national level and not at the state level. Among other things, this means that survey weights are calculated so as to replicate national, not state-level population characteristics. It is not atypical for very small states like Rhode Island or Delaware to have as few as two observations in given years whereas large states like California and New York commonly have around 200 observations per year. The signal-to-noise ratio for small states is likely to be low, and may generate substantial attenuation bias.

Commonly, the optimal (and often unavailable) solution to ascertain the reliability of a given survey-based measure is to correlate it with a measure obtained from another survey. While this solution is commonly unavailable at the individual level (as it would require independent surveying of the same individuals), it is available to us at the state-year level since we can compare state-year survey responses to the GSS and NES questions. This method also allows us to gauge the effect of different question wordings and sampling decisions on our summary state-level indicators. If these survey characteristics had a significant effect on our indicators, we would expect the correlation between the GSS and NES data to be low, while if they are not very relevant we would expect to derive a high correlation.

The upper panel of Table 1 shows the correlations between different characteristics of the state-level preference distribution for the GSS and NES data. The correlation between the mean abortion preferences of the two indicators is .413. This low correlation indicates that there appears to be considerable measurement error for our complete sample. This problem is exacerbated as one goes to the higher moments of the distribution, which typically require more observations to attain a given level of confidence. However, Table 1 also shows that a considerable part of this low correlation can be attributed to the effect of states with a small number of observations. As we drop the states with less than a minimum threshold of observations, the correlations improve significantly: when the lower threshold is 50 observations, our correlation between means from the GSS and NES indicators increases to .649, while if it is 100 observations, the correlation increases to .797. These calculations suggest that a substantial fraction of the measurement error in this variable comes from the effect of very small states. The lower panel of Table 1 also puts this problem in perspective by calculating the average widths of $95 \%$ confidence intervals that could be built around each state-level estimator of a distributional characteristic. In order to interpret these numbers, note that both the GSS and NES indices are scaled between 0 and 1. The average half-width of a confidence interval for the mean abortion preference in the whole NES sample is +/- 
0.097, whereas that for the sample restricted to $n \geq 50$ would be $+/-.058$. While the width of these intervals is far from negligible, it does suggest that the data has the ability to distinguish between conservative, moderate and liberal states.

[Insert Table 1 here]

As an indicator of enacted policy, we will use variations in abortion legislation across states. In its hallmark 1972 Roe v. Wade decision, the Supreme Court left open substantial leeway for states to regulate abortion during the second two trimesters of pregnancy. While overturning existing abortion bans, the Supreme Court argued that after the first trimester of pregnancy, states could regulate abortion in ways which are reasonably related to maternal health with the purpose of protecting the health of the mother, while in the third trimester it could regulate and even prohibit abortion, except when it was necessary to protect the health of the mother. In 1992, Casey v. Planned Parenthood of Southeastern Pennsylvania opened the door for legislation which did not impose an "undue burden " on pregnant women seeking abortions, such as informed consent laws. A number of states also passed partial birth abortion bans until these were struck down by the 2000 Stenberg v. Carhart decision. ${ }^{6}$ These decisions generated broad variations in abortion legislation across states. Our dependent variable will consist of four indicators of the restrictiveness of abortion legislation at the state level: (i) whether the state had a parental involvement law requiring notification or consent of parents for performing the abortion procedure (ii) whether the state had an informed consent law requiring abortion providers to inform pregnant women about potential health risks, the development of their unborn children, and resources available to them in case they decided not to perform the procedure (iii) whether the state adopted a partial birth abortion ban, restricting the use of the Intact Dilation and Extraction abortion procedure that is commonly only used during late-second trimester or early third trimester pregnancies, and (iv) whether the state restricts the use of Medicaid funds to fund therapeutic abortions. ${ }^{7}$

We experiment with two different ways in which to combine these four different indicators of abortion legislation into an outcome variable. The simplest approach is to generate an indicator of the number of abortion restrictions (out of these four) that the state imposed on abortion in a given year. The resulting indicator is a 0-4 count variable for which we will adopt a fixed effects Poisson specification. In

\footnotetext{
${ }^{6}$ In November, 2003, President Bush signed a National Partial Birth Abortion Ban. This statute was declared unconstitutional by federal judges in several states. However, on April 18, 2007, the US Supreme Court upheld the constitutionality of the ban.

${ }^{7}$ This data was originally collected by New (2004).
} 
order to control for correlation between our explanatory variables and unobserved state characteristics, we include state-level effects in each specification. Such an indicator, however, would assume that voters view each of these four possible restrictions as equivalent. Since this assumption may no be very appealing, we construct an additional indicator which measures the estimated reduction in abortions that can be attributed to each state's combination of abortion policies. This indicator would be a valid measure of policies if we assume that voters do not care about the restrictions per se but rather about the reduction in abortions that they may generate. Michael New (2004) has estimated the effect of these four pieces of abortion legislation on the abortion rate, and found that all four have the expected negative coefficients, with informed consent laws and Medicaid funding restrictions having a consistently significant negative effect, while partial birth and parental involvement laws have a negative yet not always significant effect. We use the expected reduction in the CDC abortion rate generated by each state's combination of abortion legislation measures as an indicator of the restrictiveness of abortion legislation. Since this variable is censored at zero, we use panel Tobit regressions to study its relation with abortion preferences. In contrast to the Poisson case, there is no consistent estimator for a fixed effects Tobit model due to the incidental parameters problem. We therefore report a random effects estimator as our baseline for this model.

\subsection{The unique equilibrium case}

\subsubsection{Baseline Panel Regressions}

Table 2 presents the results of baseline regressions with the NES indicator. The first set of columns report the panel Poisson specifications that use the number of abortion restrictions as a dependent variable, while the second set reports the Tobit specifications that use the predicted reduction in CDC abortion rate generated by these restrictions as the left-hand side variable. For each methodology, four different specifications are reported: a baseline specification that controls for the moments of the preference distribution, a second one that adds a control for the possibility that more educated voters have a greater impact on policies, a third one that adds controls for a set of environmental variables that may affect the willingness of governments to adopt abortion restrictions, and a last specification dropping the preference distribution con-

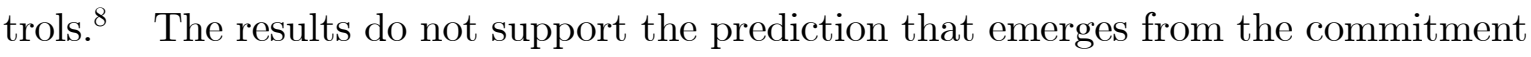

\footnotetext{
${ }^{8}$ Additional specifications (not reported) included controls for the preferences of voters with a higher level of income and those of different races. The results are broadly similar to those of the reported specifications.
} 
model of a positively sloped relationship between the preferences of constituents and enacted policies. Indeed, of the sixteen coefficients on constituent preferences reported in these tables, all of the point estimates are negative, with 8 of them attaining statistical significance at $5 \%$ and a further 3 at $10 \%$. The median population preference has a positive sign, as indicated by theory, although it is only significant at $10 \%$ in 3 of the 8 specifications.

\section{[Insert Table 2 here]}

As we have discussed above, there may be considerable measurement error arising from the fact that some of our state-level indicators are constructed with a small number of observations. Table 3 addresses this issue by repeating the same set of regressions as in Table 2, but now limited to state-years with at least 50 observations. This restricts the sample considerably, to 137 observations in 27 states. Most of the coefficient estimates increase their magnitude significantly, as would be expected if measurement error were generating attenuation bias. Again, 8 of the 16 coefficient estimates are significantly negative at 5\%, though in this subsample 7 of them pertain to the effect of changes in the preferences of democrat constituents. The median voters' preference still enters with a positive sign, which is significant at $10 \%$ or less in all 8 specifications.

\section{[Insert Table 3 here]}

Table 4 studies the results of running the same regressions using the GSS-based preference variables as our right-hand side variable. Table 4 uses the sum of responses to the seven GSS questions as an indicator of aversion to abortion and restricts to the number of individual responses in a state to be greater than 50. A principal components index as well as regressions on the full sample (not reported) delivered similar results. In the case of the GSS, we again find no evidence for the commitment model, with all of the 16 coefficient estimates on party constituent preferences being negative, 3 of them significant at $5 \%$ and another 3 at 10\%. There is again a significant difference in patterns observed between the results for democrats, which have five of the six significant coefficients, and those of republicans. Note that while this implies that the evidence that parties are in a suboptimal region of the expected policy function is stronger for democrats than for republicans, it does not imply that democrats are farther than republicans from the median voter, since there is no simple relationship between distance from the median and the slope of the expected policy function. What the results do say is that there is strong evidence that democrats could improve their electoral perspectives if they became more moderate on the abortion issue. ${ }^{9}$

\footnotetext{
${ }^{9}$ We also experimented with alternative combinations of the subcomponents of the GSS indicator that may be indicative of different dimensions of respondents' preferences over abortion legislation.
} 


\section{[Insert Table 4 here]}

To this moment, we have used a random effects Tobit specification when our dependent variable is predicted abortion. Some authors have suggested that the incidental parameters problem does not produce major inconsistencies when the number of time periods $T$ is reasonably high. Heckman and MaCurdy(1980) have argued that with $T=8$ the inconsistency is minor, whereas Greene (2004) provides Monte Carlo evidence that the Tobit model is largely unaffected by the incidental parameters problem. In Table 5 we report results of the fixed effects Tobit estimator. The table shows results for the whole sample, where the average value of $T$ is 7.53 , close to the Heckman and MaCurdy threshold (in the restricted sample $T=5.84$ ). The results again reveal a consistent negative pattern of the coefficients: all of the point estimates for the partisan preferences are negative, three of them significantly so. ${ }^{10}$

\subsubsection{Endogeneity}

We now turn to the issue of misspecification bias arising from the possible endogeneity of our right-hand side variables. As our right-hand side variables pertain to indicators of the distribution of preferences across state residents, any argument of endogeneity would have to start out from the assumption that policies can either affect preferences or be affected by a third variable that also determines preferences. One reason why this may be the case may have to do with the role of "leadership" in galvanizing support for or against policies. The adoption of policies may make it easier to mobilize support against them, particularly among politically mobilized individuals that may become inflamed when certain policies are adopted. This phenomenon could account for a negative relationship between policies and the preferences of party members.

Our proposed instruments are taken from the literature on the determination of abortion preferences (Jelen and Wilcox, 2003) and refer to variables that are unlikely to be affected by adopted policies and that nevertheless have been found to have a significant effect on abortion preferences. In particular, we choose indicators of church attendance, religious orientation, gender, race, and age of the average republican

In particular, a principal components analysis of individual-level responses to these five questions uncovered two factors with eigenvalues greater than 1, with the first component clearly influenced by responses to "imposed needs " cases which reflect situations which are out of the control of the mother, such as rape and incest, while the second component was associated with "preference based" decisions such as aborting because of a desire to have no more children or not wanting to marry.The results obtained using these two indicators as dependent variables - available from the authors upon request -are broadly similar, with the negative coefficient on democrats' preferences becoming much stronger when the imposed needs indicator is used as a dependent variable.

${ }^{10}$ Results for the restricted sample, available from the authors upon request, are very similar: all point estimates on partisan preferences are also negative, three of them significantly. 
and democrat constituents as our instruments. ${ }^{11}$ The key identification assumption should be understood as the assumption that if the average church attendance (religious orientation/age/gender/race composition) of republicans increases, holding fixed the preferences over abortion of the population as a whole, then the only effect that this will have on equilibrium policies will operate through the changes that it will effect on the preferences of republicans over abortion. Table 5 shows the results of applying the Rivers-Vuong (1988) auxiliary regression endogeneity tests with these instruments on our specification on the NES restricted sample. These tests use the residuals from a first stage regression to test for endogeneity in the second stage regression: under the hypothesis of exogeneity, the coefficient on this residual should be zero. ${ }^{12}$ We report two specifications, one with controls for environmental variables in the second stage regression, and another one without them. As shown in Table 6, the first stage F-tests are all significant at $1 \%$. None of the six endogeneity tests, in contrast, are significant at conventional levels. The tests thus provide little evidence for feedback from policies to constituent preferences. ${ }^{13}$

\section{[Insert Table 5 here]}

In the presence of endogeneity, the second stage regression yields consistent estimates of the effects of the endogenous variable. These will of course be inefficient if endogeneity is not present, as the results of Table 6 suggest. Nevertheless, it is interesting to note that the second stage results, reported in Table 7, are broadly similar to those of our previous estimation exercises: all 12 point estimates are negative, with five of them significant at 5\%. The IV estimation thus also fails to provide evidence in favor of the commitment model.

\section{[Insert Table 6 here] [Insert Table 7 here]}

\footnotetext{
${ }^{11}$ Concretely, we construct seven instruments for each party measuring the percentage of party members who are white, male, catholic, older than 61, attend church every week, almost every week or once or twice a month.

${ }^{12}$ This is an extension of the Hausmann (1978) auxiliary regression test. Smith and Blundell (1986) develop the Tobit case while Vella and Verbeek (1999) and Arendt (2001) deal with the extension to panel data.

${ }^{13}$ A comparable exercise on the GSS sample delivered very similar results: exogeneity could not be rejected in 11 of the 12 equations estimated. However, a key difference is that the first stage tests indicated very weak instruments in the GSS sample, making the results less reliable.
} 


\subsection{The multiple equilibria case}

In our theoretical section we have highlighted the potential for multiple equilibria in the commitment model. This is a general feature of many political economy models. For the empirical work done in the previous subsection to be correct one has to implicitly assume that the data is generated by a political economy model with a unique equilibrium. In this sub-section we perform tests of our comparative statics results that are robust to the presence of multiple equilibria in the underlying political economy model.

Our empirical strategy will be based on a fixed effects quantile estimator (see Koenker, 2004). Technically, the estimator requires solving:

$$
\left.\min _{\nu, \beta} \sum_{\tau=1}^{n} \sum_{i=1}^{m} \rho_{\alpha}\left(\pi_{i \tau}-\nu_{i}(\alpha)-\Pi_{i \tau}^{\prime} \beta(\alpha)\right)\right)
$$

where $\alpha$ refers to the quantile of interest, $\nu_{i}(\alpha)$ denotes a state and quantile-specific fixed effect, and $\Pi=\left[t_{l i \tau}, t_{l i \tau},, \pi_{m i \tau}, \mu_{1 i \tau}, \ldots, \mu_{n i \tau}, \ldots\right]$ is a vector of control variables ${ }^{14}$. A well-known problem in implementing (8) for discrete dependent variables is that whenever there are points of positive mass, the nonsmoothness of the objective function is not averaged out in the optimization, making it difficult to obtain the asymptotic distribution of conditional quantiles thorugh conventional methods. Machado and Santos Silva (2005) propose a smoothing methodology for count variables that consists in adding a uniformly distributed random variable to the dependent variable and averaging out the resulting estimates from a large number of replications, a method which they call "average-jittering". ${ }^{15}$ A monotone transformation of the artificial variable can be used in quantile regression estimators such as (8). Since this method has not been developed for censored regression models, we will only present estimates for the number of abortion restrictions as the dependent variable. ${ }^{16}$

Table 8 displays the results of our estimates of (8) using the average-jittered trans-

\footnotetext{
${ }^{14}$ See our discussion of the incidental parameers problem in section 4.2.1, which apply similarly to this case. Note also that in $(8)$ the fixed effect $v_{i}(\alpha)$ varies with the quantile being estimated. Koenker (2004) suggests that there is an efficiency gain from assuming a single fixed effect across quantiles and jointly estimating all quantiles. Such a characterization is inadequate when the quantiles are generated by models of multiple equilibria. This is because multiple equilibria exist when there are two values of the dependent variable corresponding to the same values of all fundamentals. The differences between equilibria will thus show up as quantile-specific unobserved heterogeneity.

${ }^{15}$ This method is implemented using the Stata QCOUNT routine of Miranda (2006).

${ }^{16}$ Our predicted abortion variable also has points of positive mass corresponding to the finite combinations of abortion restrictions that generate the prediction. Therefore standard censored quantil regression methods for continuous variables (e.g., Powell(1986)) cannot be applied. Estimation of censored quantile regressions with multiple positive mass points has - to the best of our knowledge not been adressed in the econometrics literature.
} 
form for $\alpha=\{.1, .25, .75, .9\}$. We again display results for a specification with controls and, in orded to reduce the inconsistency coming from the incidental parameters problem, use the complete sample ${ }^{17}$. The results are again inconsistent with the commitment hypothesis. For the NES data, all coefficients on partisan preferences are again negative, with five of them significantly so. For the GSS data, six of the eight coefficients are negative, with three of them significant. It does not appear that the failure of the commitment model in explaining the data can be attributed to misspecification coming from the existence of multiple equilibria.

[Insert Table 8 here]

\section{Concluding Comments}

We have argued that the cross-state abortion legislation data displays a pattern that is inconsistent with the existence of mechanisms that allow parties to make binding policy promises. Parties with the ability to precommit will never be on the downward sloping portion of the expected policy function, in which a moderation of their policy promise would move expected policies in their direction. Placing yourself in such a situation would be inconsistent with optimizing behavior, as utility could be easily increased by moderating, thus moving expected policies in your direction, while at the same time generating a safer lottery among policy alternatives. Politicians that lack the ability to credibly commit to keeping their promises, in contrast, may well find themselves on this downward sloping segment. Estimating the shape of the expected policy function that links enacted policies with the policy preferences of parties gives us a way to empirically evaluate the relevance of the credibility problem in politics.

In this paper, we have provided such a test using data on abortion legislation and preferences for a panel of US states. We find that the expected policy function appears on average to be negatively sloped. Almost all of the estimates of this slope presented in this paper were negative, with nearly half significantly so. This evidence is inconsistent with the hypothesis that politicians are able to make credible policy commitments.

Why this function is pervasively negatively sloped is an interesting fact in itself. The credibility model does not predict that this function must be negatively sloped: it only shows that it can have this slope. Recall from section 2 that the negative slope of the expected policy function corresponds to the cases in which politicians'

\footnotetext{
${ }^{17}$ See our discussion of the incidental parameters problem for the Tobit fixed effects model in section 4.2.1.
} 
preferences are too extreme for voters. If parties happen to be moderate, they will fall in the same range of the expected policy function in which credible politicians are able to position themselves. The fact that our coefficient estimates are generally negative is indicative that in equilibrium, extreme politicians not only exist but are pervasive. To understand why this is the case, one would wish to be able to study the interaction between the shape of this policy function and the process of candidate selection. Regrettably, existing models that study the entry decision together with the existence of credibility problems (Besley and Coate, 1997, Osborne and Sivlinsky, 1996) have only dealt with the case of certainty and therefore produce degenerate policy functions which are not easily amenable to empirical analysis. Further elaboration of these interactions is a promising area of future research.

\section{References}

Alesina, Alberto (1988) " "Credibility and Policy Convergence in a Two-party System with Rational Voters," American Economic Review, September, 78:796-806.

Arendt, Jacob (2002) "Endogeneity and Heterogeneity in LDV Panel Data Models," Presented at the 10th International Conference on Panel Data, Berlin, July 5-6.

Besley, T. and S. Coate (1997), An Economic Model of Representative Democracy, Quarterly Journal of Economics, 112, pp 85-114.

Chattopadhyay, Raghabendra and Esther Duflo (2004). "Women as Policy Makers: Evidence from a Randomized Policy Experiment in India," Econometrica vol. 72 no. $5,1409-1443$.

Cook, Elizabeth Adell, Ted G. Jelen, and Clyde Wilcox. 1993c. Measuring Abortion Attitudes: Methodological and Substantive Lessons From the CBS/New York Times Surveys, Family Planning Perspectives 25: 118-121, 145.

Echenique, F., and Ivana Komunjer (2005) "Testing models with multiple equilibria by quantile methods," Caltech SS Working Paper 1244.

Greene, W. H. (2004) "The Behavior of the Fixed Effects Estimator in Nonliner Models, " The Econometrics journal, 7:98-119.

Grossman, Gene and Elhanan Helpman (2002) Special Interest Politics. Cambridge: MIT Press.

Hausmann, J. A. (1978) "Specification Tests in Econometrics," Econometrica, 46, 1251-1271.

Heckman, J. J. and T. E. MaCurdy (1980) "A Life-Cycle Model of Female Labor Supply, "Review of Economic Studies, 47:47-74. 
Hinich, Melvin J. and Michael C. Munger (1997) Analtical Politics. Cambridge: Cambridge University Press.

Jelen, Ted G. and Clyde Wilcox (2003) "Causes and Consequences of Public Attitudes Toward Abortion: A Review and Research Agenda. " Reproduced, Georgetown University.

Koenker, Roger (2004) "Quantile Regression for Longitudinal Data," J. of Multivariate Analysis, (2004), 91, 74-89.

Lee, D. S., Moretti, E. and Butler, M. J. (2004), 'Do Voters Affect or Elect Policies? Evidence from the U.S. House', Quarterly Journal of Economics 119(3), 807-859.

Machado, José A. F. and J.M.C. Santos Silva (2005) "Quantiles for counts." Journal of the American Statistical Association, December, 100(472): 1226-1237

Miranda, Alfonso (2006) "QCOUNT: Stata program to fit quantile regression models for count data". Electronic file, http://econpapers.repec.org/software/ bocbocode/s456714.htm.

Mueller, Dennis (2003) Public Choice III. Cambridge: Cambridge University Press.

New. Michael (2004) "Analyzing the effects of state legislation on the incidence of abortion during the 1990s" Washington, DC: The Heritage Foundation.

Osborne M.J. and A. Slivinsky (1996) "A model of Political Competition with Citizen-Candidates" Quarterly Journal of Economics 111, 64-96.

Powell, J. L. (1986) "Censored Regression Quantiles, "Journal of Econometrics, 32: $143-55$.

Rivers, D., and H. Vuong (1988) "Limited Information Estimators and Exogeneity Tests for Simultaneous Probit Models" Journal of Econometrics, Vol. 39: 347-366

Roemer, John (1997) "Political-economic equilibrium when parties represent constituents: The unidimensional case." Social Choice and Welfare 14, 479-502.

Roemer, John (2001) Political Competition. Cambridge: Harvard University Press.

Smith, R.J. and R. W. Blundell (1986) "An Exogeneity Test for a Simultaneous Equation Tobit Model with an Application to Labor Supply," Econometrica, 54,679685 .

Vella, Francis and Marno Verbeek (1999) "Two-step estimation of panel data models with censored endogenous variables and selection bias," Journal of Econometrics, 90, 239-263.

Wittman, Donald (1973) "Parties as utility maximizers, " American Political Science Review 67: 490-98.

White, Theodore H. (1973) , The Making of the President 1972. Antheneum Publishers. 


$$
j
$$



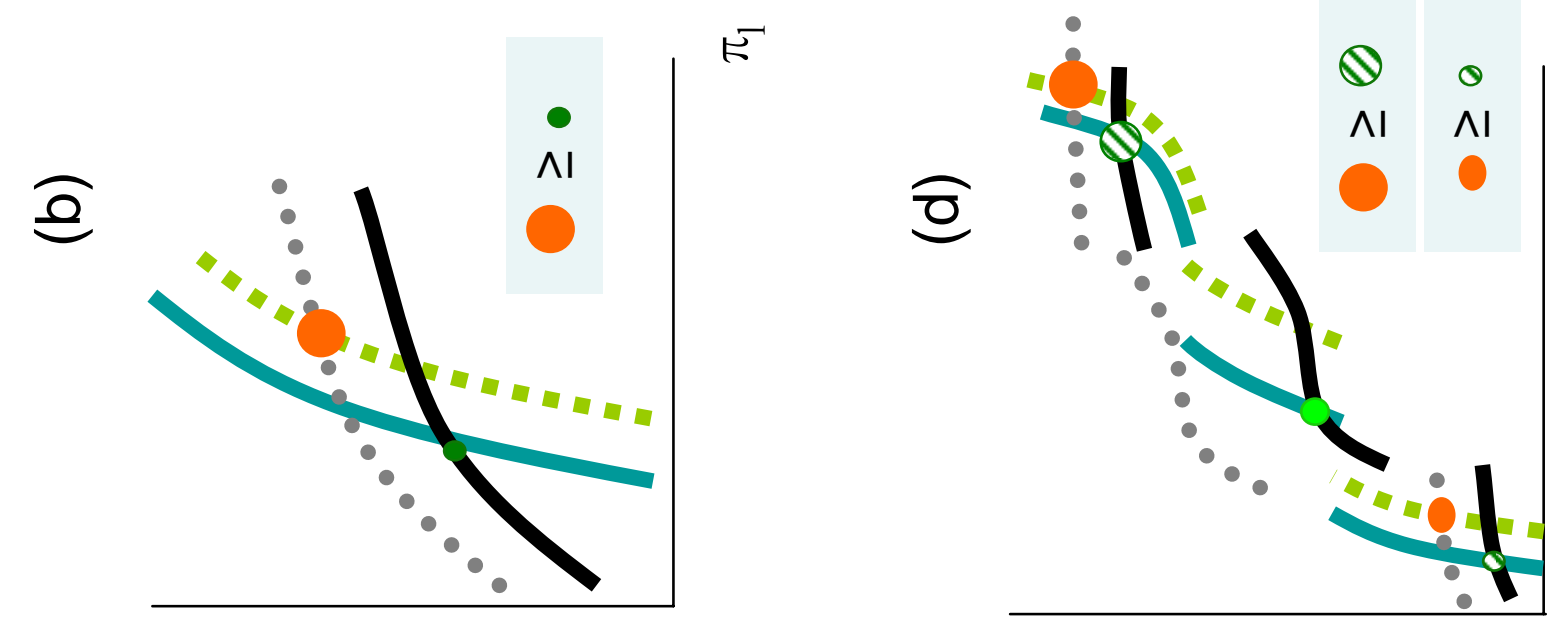

$\kappa^{H}$

$k^{H}$

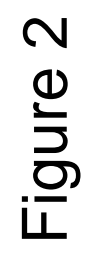
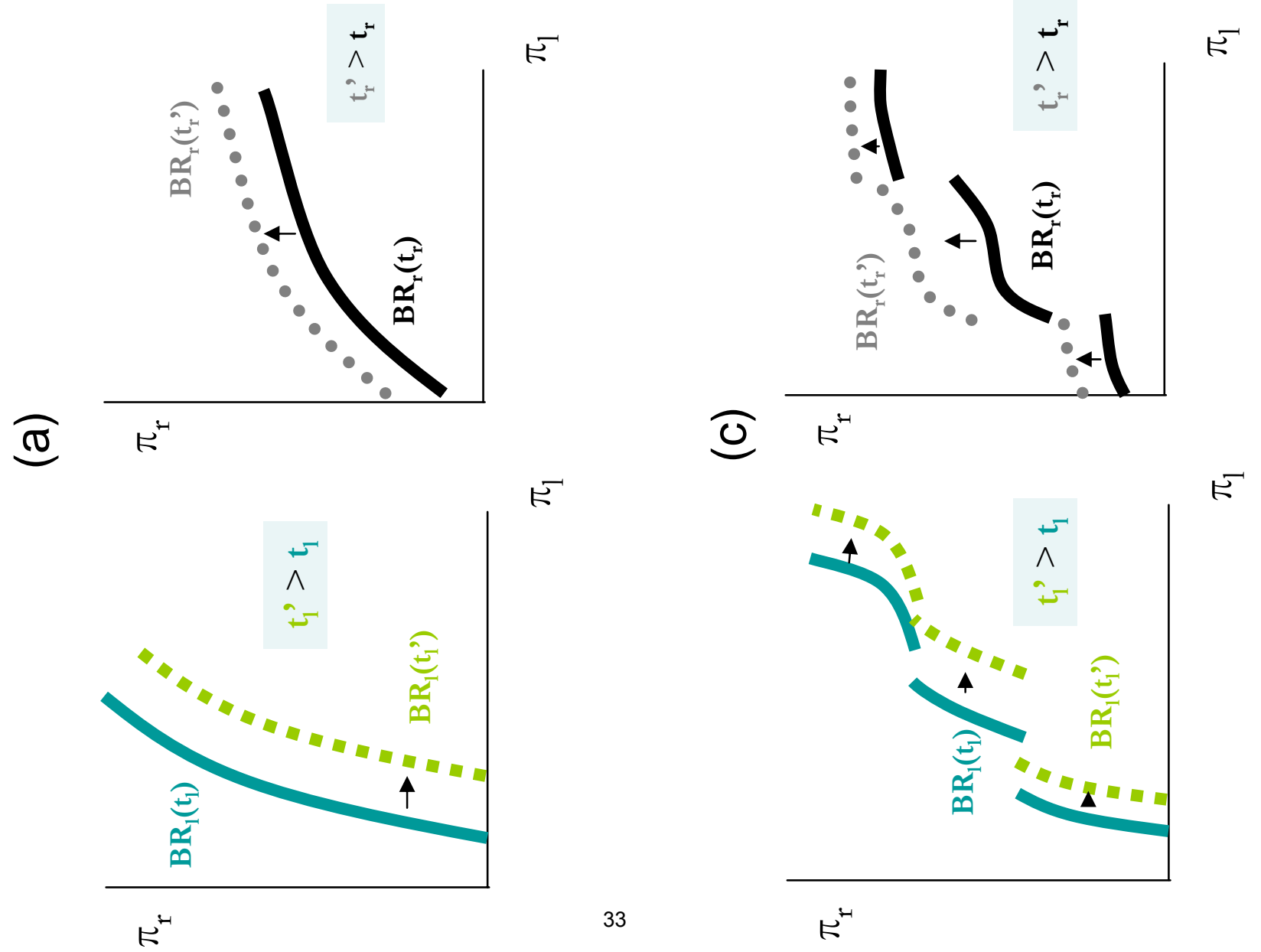

5

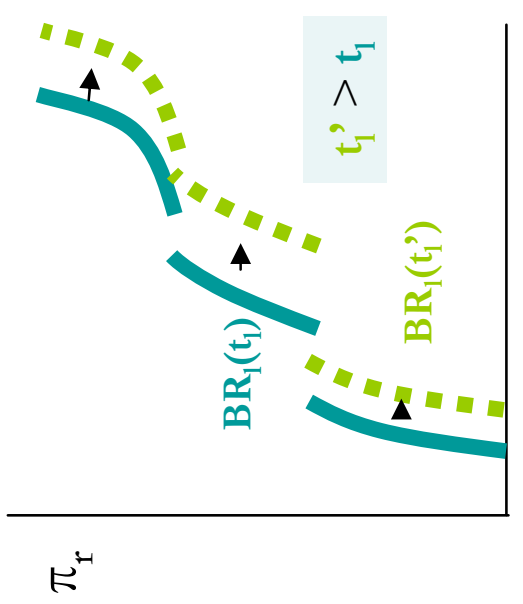

E 


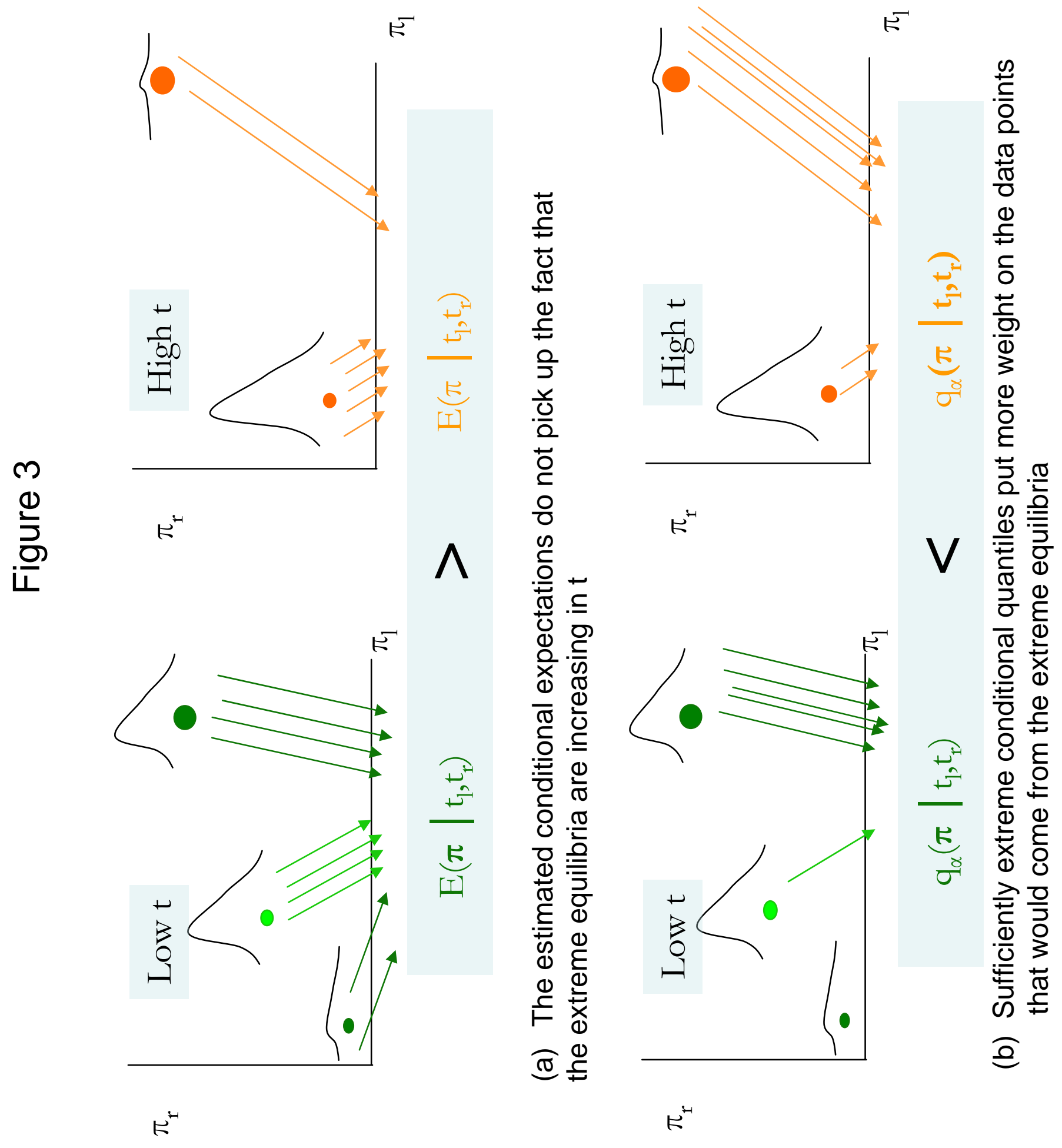




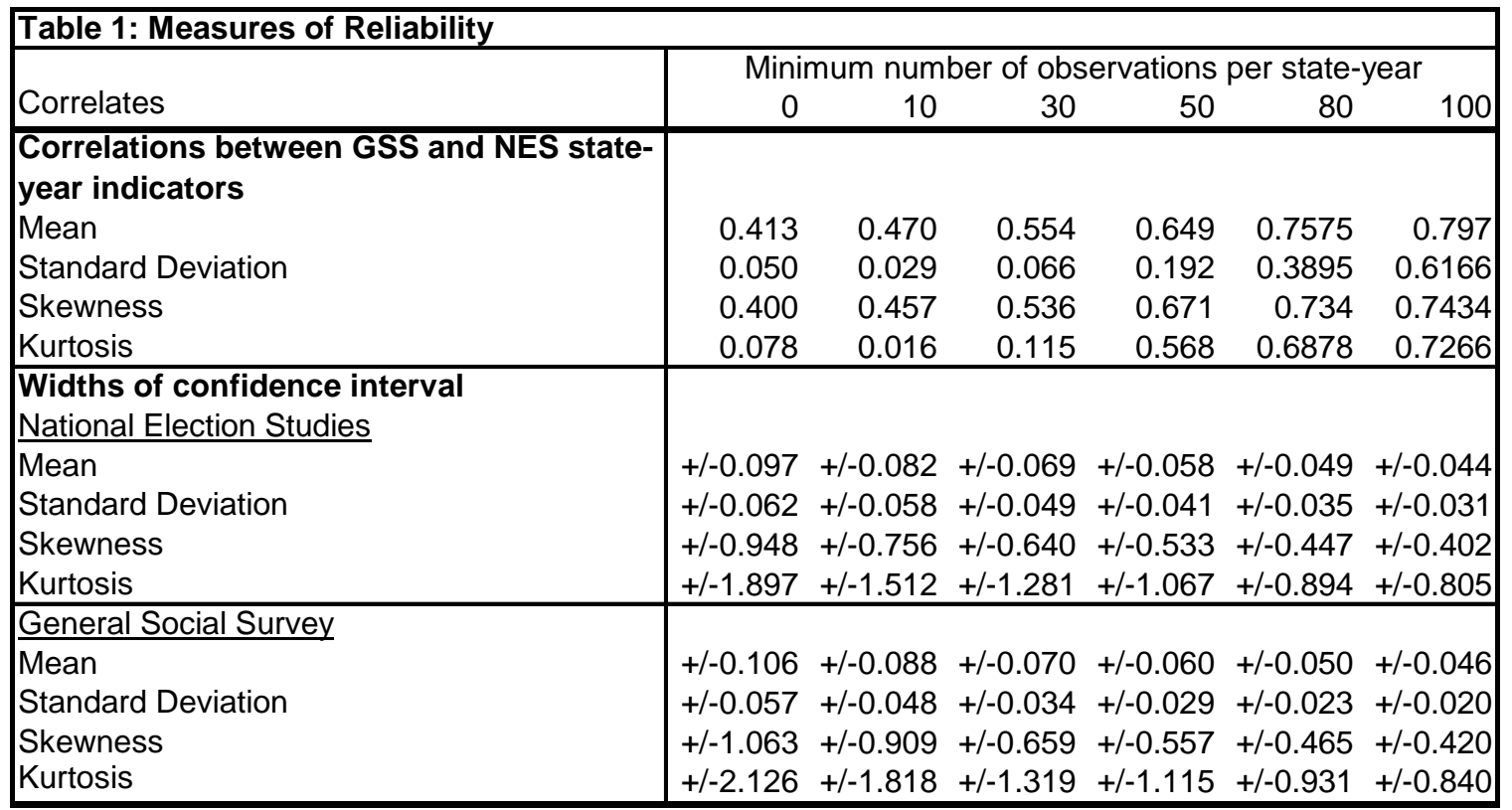

Note: Both the NES and GSS indicators are normalized to lie in the $0-1$ range 
Table 2: Complete Sample Regressions, National Election Studies

\begin{tabular}{|c|c|c|c|c|c|c|c|c|}
\hline & \multicolumn{4}{|c|}{ Poisson Fixed Effects } & \multicolumn{4}{|c|}{ Tobit Random Effects } \\
\hline Specification & 1 & 2 & 3 & 4 & 1 & 2 & 3 & 4 \\
\hline Dependent Variable & Number of les & gislative restri & ctions (0-4) & & Abortion-redu & ng effect of & gal restricti & ons \\
\hline Median & $\begin{array}{r}0.3199 \\
(0.2198)\end{array}$ & $\begin{array}{r}0.3123 \\
(0.2158)\end{array}$ & $\begin{array}{r}0.3104 \\
(0.2100)\end{array}$ & $\begin{array}{r}0.3066 \\
(0.1622)^{\star}\end{array}$ & $\begin{array}{r}0.8075 \\
(0.4723)^{\star}\end{array}$ & $\begin{array}{r}0.835 \\
(0.4652)^{\star}\end{array}$ & $\begin{array}{r}0.8594 \\
(0.6384)\end{array}$ & $\begin{array}{r}0.7554 \\
(0.4233)^{\star}\end{array}$ \\
\hline Median republicans & -0.3212 & -0.317 & -0.3592 & -0.3351 & -0.5459 & -0.5098 & -0.5771 & -0.5526 \\
\hline & $(0.1065)^{\star \star \star}$ & $(0.1076)^{\star \star \star}$ & $(0.0869)^{\star \star \star}$ & $(0.0696)^{\star \star \star}$ & $(0.2529)^{\star \star}$ & $(0.3261)$ & $(0.2964)^{\star}$ & $(0.1896)^{\star \star \star}$ \\
\hline Median democrats & -0.2483 & -0.2663 & -0.2292 & -0.2169 & -0.3949 & -0.4098 & -0.4399 & -0.4414 \\
\hline & $(0.1202)^{\star \star}$ & $(0.1219)^{\star \star}$ & $(0.1375)^{\star}$ & $(0.1302)^{\star}$ & (0.2889) & $(0.2953)$ & $(0.2840)$ & $(0.2629)^{\star}$ \\
\hline Mean & $\begin{array}{r}1.4302 \\
(1.0327)\end{array}$ & $\begin{array}{r}1.7134 \\
(1.0900)\end{array}$ & $\begin{array}{r}1.2545 \\
(1.0591)\end{array}$ & & $\begin{array}{r}0.9671 \\
(1.7544)\end{array}$ & $\begin{array}{r}1.2034 \\
(2.1975)\end{array}$ & $\begin{array}{r}1.2036 \\
(1.8508)\end{array}$ & \\
\hline Standard Deviation & $\begin{array}{r}0.3351 \\
(1.2447)\end{array}$ & $\begin{array}{r}0.516 \\
(1.2060)\end{array}$ & $\begin{array}{r}0.0971 \\
(1.2112)\end{array}$ & & $\begin{array}{r}-2.8223 \\
(2.2491)\end{array}$ & $\begin{array}{r}-2.8929 \\
(2.1377)\end{array}$ & $\begin{array}{r}-2.2794 \\
(2.8108)\end{array}$ & \\
\hline Skewness & 0.2323 & 0.2457 & 0.2205 & & 0.277 & 0.269 & 0.2952 & \\
\hline & (0.1829) & $(0.1770)$ & $(0.1499)$ & & $(0.2638)$ & $(0.2719)$ & $(0.1872)$ & \\
\hline Kurtosis & $\begin{array}{r}0.0664 \\
(0.0728)\end{array}$ & 0.0678 & 0.0332 & & 0.148 & 0.1537 & 0.1236 & \\
\hline Interquartile & $\begin{array}{r}-0.196 \\
(0.1749)\end{array}$ & $\begin{array}{r}-0.1814 \\
(0.1832)\end{array}$ & $\begin{array}{r}(0.0704) \\
-0.2057 \\
(0.1887)\end{array}$ & & $\begin{array}{r}(0.1932) \\
0.3545 \\
(0.5075)\end{array}$ & $\begin{array}{r}(0.1 / 78) \\
0.4146 \\
(0.4755)\end{array}$ & $\begin{array}{r}(0.1404) \\
0.1261 \\
(0.5372)\end{array}$ & \\
\hline $\begin{array}{l}\text { Median College } \\
\text { Educated }\end{array}$ & & $\begin{array}{r}-0.0943 \\
(0.1024)\end{array}$ & & & & $\begin{array}{r}-0.3236 \\
(0.2713)\end{array}$ & & \\
\hline $\begin{array}{l}\text { Proportion of } \\
\text { females 15-44 }\end{array}$ & & & $\begin{array}{c}-11.2928 \\
(6.7412)^{\star}\end{array}$ & $\begin{array}{r}-12.0009 \\
(4.7732)^{\star \star}\end{array}$ & & & $\begin{array}{r}4.8817 \\
(7.9792)\end{array}$ & $\begin{array}{r}4.0167 \\
(9.9959)\end{array}$ \\
\hline $\begin{array}{l}\text { Log of Per Capita } \\
\text { Real Gross State }\end{array}$ & & & & & & & & \\
\hline Product & & & $\begin{array}{r}0.3406 \\
(0.3985)\end{array}$ & $\begin{array}{r}0.3152 \\
(0.3759)\end{array}$ & & & $\begin{array}{r}1.13 \\
(1.5256)\end{array}$ & $\begin{array}{r}1.0978 \\
(1.6120)\end{array}$ \\
\hline $\begin{array}{l}\text { Log of } \\
\text { Intergovernmental }\end{array}$ & & & & & & & & \\
\hline & & & $\begin{array}{r}0.2399 \\
(0.2099)\end{array}$ & $\begin{array}{r}0.2498 \\
(0.1966)\end{array}$ & & & $\begin{array}{r}0.5805 \\
(0.5047)\end{array}$ & $\begin{array}{r}0.6496 \\
(0.5180)\end{array}$ \\
\hline Constant & & & & & $\begin{array}{r}-1.5485 \\
(1.6227)\end{array}$ & $\begin{array}{r}-1.4983 \\
(1.9634)\end{array}$ & $\begin{array}{r}-18.8099 \\
(18.1237)\end{array}$ & $\begin{array}{r}-17.9535 \\
(16.0039)\end{array}$ \\
\hline & 320 & 318 & 320 & 320 & 323 & 321 & 323 & 324 \\
\hline N. Groups & 39 & 39 & 39 & 39 & 42 & 42 & 42 & 43 \\
\hline
\end{tabular}

Note: All regressions include period dummies. Bootstrapped panel-consistent standard errors, generated with 50 replications, in parentheses. ${ }^{*}, *$ and ${ }^{* * *}$ indicate significance tests at the $10 \%, 5 \%$, and $1 \%$ levels, respectively. 
Table 3: Restricted Sample Regressions, National Election Studies

\begin{tabular}{|c|c|c|c|c|c|c|c|c|}
\hline & \multicolumn{4}{|c|}{ Poisson Fixed Effects } & \multicolumn{4}{|c|}{ Tobit Random Effects } \\
\hline Specification & 1 & 2 & 3 & 4 & 1 & 2 & 3 & 4 \\
\hline Dependent Variable & Number of le & gislative restri & ictions (0-4) & & Abortion-redu & ing effect of & legal restrictic & ons \\
\hline Median & $\begin{array}{c}0.8049 \\
(0.3390)^{\star \star}\end{array}$ & $\begin{array}{r}0.8023 \\
(0.3029)^{\star * \star}\end{array}$ & $\begin{array}{r}0.8583 \\
(0.3208)^{\star \star \star}\end{array}$ & $\begin{array}{r}0.9127 \\
(0.2394)^{\star \star \star}\end{array}$ & $\begin{array}{r}1.3285 \\
(0.7652)^{\star}\end{array}$ & $\begin{array}{r}1.336 \\
(0.7378)^{*}\end{array}$ & $\begin{array}{r}1.3172 \\
(0.7179)^{\star}\end{array}$ & $\begin{array}{r}1.5904 \\
(0.6655)^{\star *}\end{array}$ \\
\hline Median republicans & $\begin{array}{l}-0.3195 \\
(0.2100)\end{array}$ & $\begin{array}{r}-0.3271 \\
(0.2293)\end{array}$ & $\begin{array}{r}-0.3664 \\
(0.2245)\end{array}$ & $\begin{array}{r}-0.3273 \\
(0.1467)^{\star \star}\end{array}$ & $\begin{array}{r}-0.8856 \\
(0.6541)\end{array}$ & $\begin{array}{r}-0.9054 \\
(0.7878)\end{array}$ & $\begin{array}{r}-0.7178 \\
(0.7924)\end{array}$ & $\begin{array}{r}-0.4884 \\
(0.5116)\end{array}$ \\
\hline Median democrats & $\begin{array}{r}-0.5619 \\
(0.1833)^{\star \star \star}\end{array}$ & $\begin{array}{r}-0.5747 \\
(0.2032)^{\star \star \star}\end{array}$ & $\begin{array}{r}-0.5867 \\
(0.2045)^{\star \star \star}\end{array}$ & $\begin{array}{r}-0.5278 \\
(0.1272)^{\star \star \star}\end{array}$ & $\begin{array}{r}-1.178 \\
(0.5193)^{\star \star}\end{array}$ & $\begin{array}{l}-1.1966 \\
(0.7278)\end{array}$ & $\begin{array}{c}-1.173 \\
(0.5205)^{\star \star}\end{array}$ & $\begin{array}{r}-1.0541 \\
(0.4143)^{\star \star}\end{array}$ \\
\hline Mean & $\begin{array}{r}-0.746 \\
(2.5201)\end{array}$ & $\begin{array}{r}-0.5672 \\
(3.0089)\end{array}$ & $\begin{array}{r}-0.7902 \\
(2.4516)\end{array}$ & & $\begin{array}{r}6.0839 \\
(8.9287)\end{array}$ & $\begin{array}{r}5.445 \\
(10.7917)\end{array}$ & $\begin{array}{r}2.3378 \\
(9.5477)\end{array}$ & \\
\hline Standard Deviation & $\begin{array}{r}-3.3328 \\
(2.8361)\end{array}$ & $\begin{array}{r}-3.1679 \\
(2.7199)\end{array}$ & $\begin{array}{r}-2.4955 \\
(3.3641)\end{array}$ & & $\begin{array}{r}0.8278 \\
(9.7265)\end{array}$ & $\begin{array}{r}0.0252 \\
(12.5608)\end{array}$ & $\begin{array}{r}-0.9592 \\
(12.1030)\end{array}$ & \\
\hline Skewness & $\begin{array}{l}-0.2003 \\
(0.4252)\end{array}$ & $\begin{array}{r}-0.1887 \\
(0.4560)\end{array}$ & $\begin{array}{l}-0.2454 \\
(0.4143)\end{array}$ & & $\begin{array}{r}0.6483 \\
(1.7061)\end{array}$ & $\begin{array}{r}0.587 \\
(1.9094)\end{array}$ & $\begin{array}{r}0.1096 \\
(1.6645)\end{array}$ & \\
\hline Kurtosis & $\begin{array}{r}-0.0685 \\
(0.2073)\end{array}$ & $\begin{array}{r}-0.0609 \\
(0.1926)\end{array}$ & $\begin{array}{r}-0.0899 \\
(0.2518)\end{array}$ & & $\begin{array}{r}0.4221 \\
(0.8319)\end{array}$ & $\begin{array}{r}0.3181 \\
(0.9655)\end{array}$ & $\begin{array}{r}0.1656 \\
(0.7930)\end{array}$ & \\
\hline Interquartile & $\begin{array}{r}0.1153 \\
(0.2780)\end{array}$ & $\begin{array}{r}0.1286 \\
(0.2990)\end{array}$ & $\begin{array}{r}0.0748 \\
(0.2549)\end{array}$ & & $\begin{array}{r}0.4381 \\
(0.6709)\end{array}$ & $\begin{array}{r}0.4315 \\
(0.9140)\end{array}$ & $\begin{array}{r}0.4136 \\
(0.7115)\end{array}$ & \\
\hline $\begin{array}{l}\text { Median College } \\
\text { Educated }\end{array}$ & & $\begin{array}{r}-0.0508 \\
(0.1250)\end{array}$ & & & & $\begin{array}{r}-0.0004 \\
(0.4635)\end{array}$ & & \\
\hline $\begin{array}{l}\text { Proportion of } \\
\text { females 15-44 } \\
\text { Log of Per Capita } \\
\text { Real Gross State }\end{array}$ & & & $\begin{array}{r}15.5011 \\
(14.0795)\end{array}$ & $\begin{array}{r}15.7888 \\
(12.3313)\end{array}$ & & & $\begin{array}{c}28.0969 \\
(14.1907)^{\star \star}\end{array}$ & $\begin{array}{r}29.4186 \\
(15.4681)^{\star}\end{array}$ \\
\hline $\begin{array}{l}\text { Product } \\
\text { Log of } \\
\text { Intergovernmental }\end{array}$ & & & $\begin{array}{r}-0.2316 \\
(1.0576)\end{array}$ & $\begin{array}{r}-0.299 \\
(0.7534)\end{array}$ & & & $\begin{array}{r}1.6051 \\
(2.4467)\end{array}$ & $\begin{array}{r}1.3435 \\
(2.0640)\end{array}$ \\
\hline Aid & & & $\begin{array}{r}0.6676 \\
(0.2616)^{\star \star}\end{array}$ & $\begin{array}{r}0.6921 \\
(0.1946)^{\star \star \star}\end{array}$ & & & $\begin{array}{r}0.5783 \\
(1.0181)\end{array}$ & $\begin{array}{r}0.4689 \\
(0.9717)\end{array}$ \\
\hline Constant & & & & & $\begin{array}{r}-5.5307 \\
(9.3009) \\
\end{array}$ & $\begin{array}{r}-4.6914 \\
(11.3919) \\
\end{array}$ & $\begin{array}{r}-34.934 \\
(28.4712) \\
\end{array}$ & $\begin{array}{r}-30.8155 \\
(21.2148) \\
\end{array}$ \\
\hline & 132 & 132 & 132 & 132 & 137 & 137 & 137 & 137 \\
\hline N. Groups & 22 & 22 & 22 & 22 & 27 & 27 & 27 & 27 \\
\hline
\end{tabular}

Note:All regressions include period dummies. Bootstrapped panel-consistent standard errors, generated with 50 replications, in parentheses.*,** and ${ }^{* * *}$ indicate significance tests at $10 \%, 5 \%$, and $1 \%$ levels, respectively. 
Table 4: Restricted Sample Regressions, General Social Survey

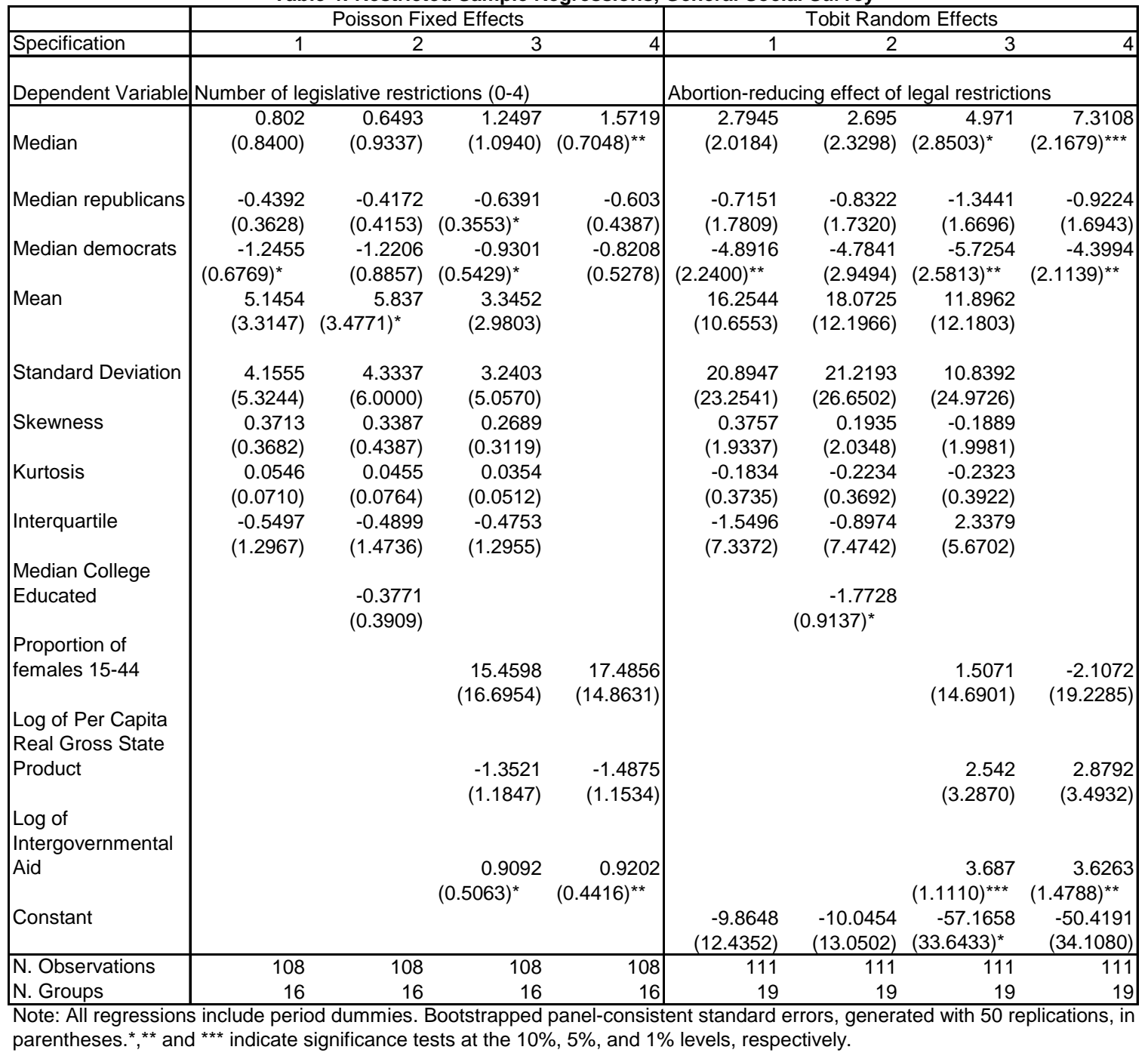


Table 5: Fixed Effects Tobit Estimators, Complete Sample

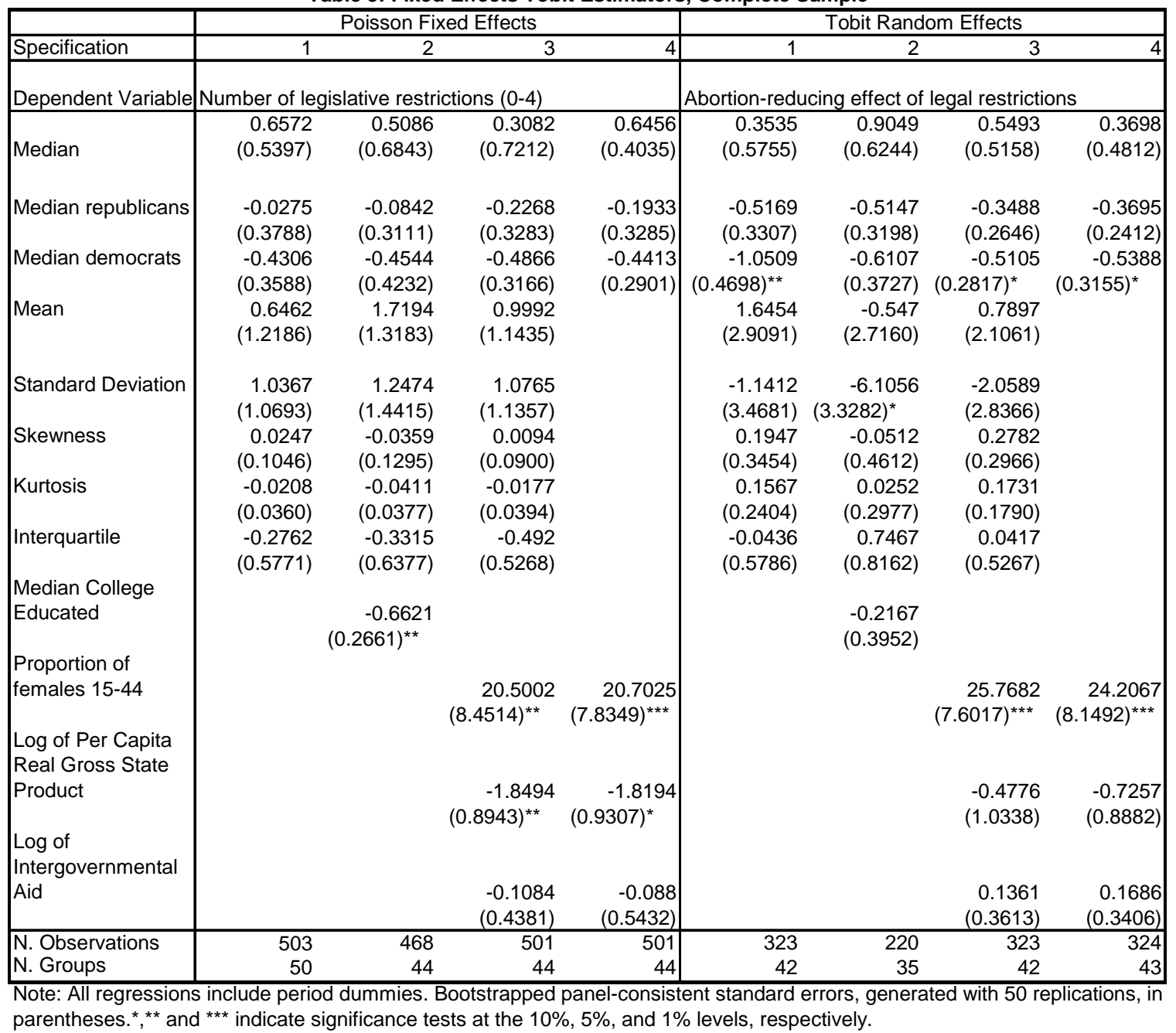


Table 6: Auxiliary Regression Endogeneity Test, National Election Studies

\begin{tabular}{|c|cl|cc|}
\hline \multicolumn{2}{|c}{} & \multicolumn{2}{c|}{ Without controls } & With controls \\
\hline \multirow{2}{*}{$\begin{array}{c}\text { First Stage Instruments } \\
\text { Significance }\end{array}$} & Democrats & 0.0006 & 0.0008 \\
\cline { 2 - 5 } & Republicans & 0.0083 & 0.0069 \\
\hline \multirow{3}{*}{ Endogeneity test } & Democrats & Poisson & 0.5500 & 0.3330 \\
& & Tobit & 0.3240 & 0.7400 \\
\cline { 2 - 5 } & \multirow{2}{*}{ Republicans } & Poisson & 0.1000 & 0.2850 \\
\cline { 2 - 5 } & & Tobit & 0.3310 & 0.1580 \\
\cline { 2 - 5 } & \multirow{2}{*}{ Joint } & Poisson & 0.1228 & 0.2990 \\
& Tobit & 0.5876 & 0.2130 \\
\hline
\end{tabular}

Note: First stage estimated by maximum likelihood. P-values correspond to Wald tests based on bootstrapped panelconsistent standard errors, generated with 50 replications. 
Table 7: Second Stage Estimates, National Election Studies

\begin{tabular}{|c|l|rr|}
\hline \multirow{2}{*}{ Endogeneity Control } & Specification & Democrat Median & Republican Median \\
\hline \multirow{3}{*}{ Democrats } & Poisson & -0.8976 & -0.4070 \\
& & $(0.6485)$ & $(0.328)$ \\
& Tobit & -3.5390 & -1.4080 \\
& & $(2.1454)^{\star}$ & $(1.0515)$ \\
\hline & Poisson & -0.8267 & -0.9856 \\
Republicans & & $(0.1897)^{\star \star \star}$ & $(0.4007)^{\star \star}$ \\
& Tobit & -1.7193 & -2.5624 \\
& & $(0.706)^{\star \star}$ & $(1.6606)$ \\
\hline \multirow{2}{*}{ Joint } & Poisson & -1.2234 & -1.1081 \\
& & $(0.5074)^{\star \star}$ & $(0.4284)^{\star \star}$ \\
& Tobit & -3.5933 & -1.6423 \\
& & $(2.5076)$ & $(1.8375)$ \\
\hline
\end{tabular}

Note: Bootstrapped panel-consistent standard errors, generated with 50 replications, in parentheses. ${ }^{\star},{ }^{\star \star}$ and *** indicate significance tests at the $10 \%, 5 \%$, and $1 \%$ levels, respectively. 
Table 8: Quantile Regressions for Number of Legislative Restrictions, Complete Sample

\begin{tabular}{|c|c|c|c|c|c|c|c|c|}
\hline & & National Elec & tion Studies & & & General So & cial Survey & \\
\hline \begin{tabular}{|l|} 
Specification \\
\end{tabular} & $(1)$ & $(2)$ & $(3)$ & (4) & $(5)$ & $(6)$ & $(7)$ & $(8)$ \\
\hline Percentile & 10 & 25 & 75 & 90 & 10 & 25 & 75 & 90 \\
\hline Median & $\begin{array}{c}0.2682 \\
(0.1502)^{\star}\end{array}$ & $\begin{array}{l}0.2868 \\
(0.194)\end{array}$ & $\begin{array}{l}0.1549 \\
(0.160)\end{array}$ & $\begin{array}{r}0.0948 \\
(0.126)\end{array}$ & $\begin{array}{c}0.1535 \\
(0.0791)^{\star}\end{array}$ & $\begin{array}{c}0.1292 \\
(0.0490)^{\star \star \star}\end{array}$ & $\begin{array}{r}-0.0226 \\
(0.114)\end{array}$ & $\begin{array}{r}-0.0547 \\
(0.088)\end{array}$ \\
\hline & -0.258 & -0.2971 & -0.3015 & -0.1908 & -0.0431 & -0.0275 & 0.0489 & 0.043 \\
\hline Median republicans & $(0.0546)^{\star \star \star}$ & $(0.0878)^{\star \star \star}$ & $(0.1310)^{\star \star}$ & $(0.0881)^{\star \star}$ & $(0.044)$ & $(0.031)$ & $(0.054)$ & $(0.030)$ \\
\hline & -0.0824 & -0.2182 & -0.1885 & -0.1626 & -0.1929 & -0.1502 & -0.1308 & -0.063 \\
\hline Median democrats & $(0.058)$ & $(0.0965)^{\star \star}$ & $(0.160)$ & $(0.113)$ & $(0.0381)^{\star \star \star}$ & $(0.0318)^{\star \star \star}$ & $(0.0230)^{\star \star \star}$ & $(0.042)$ \\
\hline & 0.3839 & 1.5011 & 0.657 & 0.3355 & 0.425 & 0.5316 & 0.5173 & 0.2701 \\
\hline Mean & $(0.425)$ & $(0.3163)^{\star \star \star}$ & $(0.822)$ & $(1.809)$ & $(0.1448)^{\star \star \star}$ & $(0.1063)^{\star \star \star}$ & $(0.0812)^{\star \star \star}$ & $(0.0807)^{\star \star \star}$ \\
\hline & 0.0883 & 0.6204 & -0.1227 & -0.0704 & 1.1127 & 1.0158 & 0.6814 & 0.4646 \\
\hline Standard Deviation & $(0.437)$ & $(0.568)$ & $(0.681)$ & (1.615) & $(0.2160)^{\star \star \star}$ & $(0.2231)^{\star \star \star}$ & $(0.1187)^{\star \star \star}$ & $(0.0912)^{\star \star \star}$ \\
\hline & 0.1041 & 0.2868 & 0.0936 & 0.0353 & 0.0231 & 0.0299 & 0.0173 & -0.0003 \\
\hline Skewness & $(0.0527)^{\star \star}$ & $(0.0776)^{\star \star \star}$ & $(0.0562)^{*}$ & $(0.388)$ & $(0.0079)^{\star \star \star}$ & $(0.0112)^{\star \star \star}$ & $(0.012)$ & $(0.010)$ \\
\hline & 0.0136 & 0.0444 & 0.0089 & -0.0159 & -0.0102 & -0.0011 & -0.0026 & -0.0094 \\
\hline Kurtosis & $(0.041)$ & $(0.0199)^{\star \star}$ & $(0.072)$ & $(0.183)$ & $(0.0049)^{\star \star}$ & $(0.005)$ & $(0.005)$ & $(0.0044)^{\star \star}$ \\
\hline & -0.2315 & -0.2693 & -0.1836 & -0.2565 & -0.4538 & -0.2916 & -0.135 & -0.1535 \\
\hline Interquartile & $(0.173)$ & $(0.0534)^{\star \star \star}$ & $(0.144)$ & $(0.1278)^{\star \star}$ & $(0.0906)^{\star \star \star}$ & $(0.0851)^{\star \star \star}$ & $(0.0759)^{\star}$ & $(0.0660)^{\star \star}$ \\
\hline Proportion of & -6.7694 & -14.5054 & -10.8161 & -8.9462 & 5.5042 & 0.5202 & 1.4808 & 1.9492 \\
\hline females 15-44 & $(1.1913)^{\star \star \star}$ & $(4.0061)^{\star \star \star}$ & $(3.6706)^{\star \star \star}$ & $(5.612)$ & $(1.1054)^{\star \star \star}$ & $(2.293)$ & $(1.462)$ & $(1.1644)^{\star}$ \\
\hline Log of Per Capita & & & & & & & & \\
\hline Real Gross State & 0.4051 & 0.4988 & 0.6505 & 0.4385 & -0.359 & -0.2649 & -0.2554 & -0.2593 \\
\hline Product & $(0.1485)^{\star \star \star}$ & $(0.1135)^{\star \star \star}$ & $(0.3452)^{\star}$ & $(0.530)$ & $(0.0511)^{\star \star \star}$ & $(0.1145)^{\star \star}$ & $(0.1111)^{\star \star}$ & $(0.1117)^{\star \star}$ \\
\hline $\begin{array}{l}\text { Log of } \\
\text { Intergovernmental }\end{array}$ & 0.3356 & 0.335 & 0.1993 & 0.1913 & -0.1539 & -0.2183 & 1542 & -00867 \\
\hline Aid & $(0.0590)^{\star \star \star}$ & $(0.1035)^{\star \star \star}$ & $(0.213)$ & $(0.200)$ & $(0.0669)^{\star \star}$ & $(0.0690)^{\star \star \star}$ & $(0.0387)^{\star \star \star}$ & $(0.0328)^{\star \star \star}$ \\
\hline N. Observa & 323 & 323 & 323 & 323 & 501 & 501 & 501 & 501 \\
\hline N. Groups & 42 & 42 & 42 & 42 & 44 & 44 & 44 & 44 \\
\hline
\end{tabular}

Estimation uses the average-jittering method of Machado and Santos Silva (2005). Bootstrapped panel-consistent standard errors in parenthesis. Each estimation uses 10 replications for each jittered estimate and 100 bootstrap replications, for a total of 1000 independent draws. All regressions include time and state-specific effects. 